Author version: Meteor. Planet. Sci., vol.50 (6); 2015; 1013-1031

\title{
ORDINARY CHONDRITIC MICROMETEORITES FROM THE INDIAN OCEAN
}

\author{
M. Shyam Prasad*, N.G. Rudraswami, Agnelo De Araujo, \\ CSIR - National Institute of Oceanography, Dona Paula, Goa -403004, INDIA \\ *shyam@nio.org

\section{E.V.S.S.K. Babu and T. Vijaya Kumar} \\ LAM-ICP-MS National Facility, CSIR-National Geophysical Research Institute \\ Uppal Road, Hyderabad - 500007, INDIA
}

\begin{abstract}
Extraterrestrial particulate materials on the Earth can originate in the form of collisional debris from the asteroid belt, cometary material or as meteoroid ablation spherules. Signatures that link them to their parent bodies become obliterated if the frictional heating is severe during atmospheric entry. We investigated 481 micrometeorites isolated from $\sim 300 \mathrm{~kg}$ of deepsea sediment, out of which 15 spherules appear to have retained signatures of their provenance, based on their textures, bulk chemical compositions and relict grain compositions. Seven out of these 15 spherules contain chromite grains whose compositions help in distinguishing sub-groups within the ordinary chondrite sources. There are seven other spherules which comprise either entirely of dusty olivines or contain dusty olivines as relict grains. Two of these spherules appear to be chondrules from an unequilibrated ordinary chondrite. In addition, a POP (porphyritic olivine pyroxene) chondrule-like spherule is also recovered. The bulk chemical composition of all the spherules, in combination with trace elements, the chromite composition and presence of dusty olivines suggest an ordinary chondritic source. These micrometeorites have undergone minimal frictional heating during their passage through the atmosphere and have retained these features. These micrometeorites therefore also imply there is a significant contribution from ordinary chondritic sources to the micrometeorite flux on the Earth.
\end{abstract}




\section{INTRODUCTION}

In view of the sheer quantity that rain on the Earth, micrometeorites overlap and extend the range of the known meteorite types, therefore constitute an extremely valuable resource of extraterrestrial material. Estimates on the quantity of micrometeorites that impact the top of Earth's atmosphere are varied (Cremonese et al., 2012; Peucker-Ehrenbrink and Ravizza, 2000; Love and Brownlee, 1993). More than $90 \%$ of this material undergoes frictional heating and vaporization during atmospheric entry, therefore the surviving particulate matter provides an important window to understand the components of the Earth-crossing meteoroid complex. Preservation of micrometeorites that survive atmospheric entry depends on the environments where they are collected. The polar regions, in view of the prevailing cryogenic conditions, are now realized as the treasure houses of vast numbers and varieties of micrometeorites (e.g., Kurat et al., 1994; Taylor et al., 2000; 2012; van Ginneken et al., 2012). The fluxes of micrometeorites that survived atmospheric entry recorded in the polar regions are also among the highest in terrestrial environments (e.g., Yada et al., 2004). Due to low sedimentation rates, deep sea regions facilitate collection of micrometerorite material. They also have the potential to provide information on the micrometeorite flux and components on the scale of tens to hundreds of thousands of years (Prasad et al. 2013; Taylor and Brownlee, 1991).

Micrometeorites are found either as unmelted/partially melted or a fully melted cosmic spherules. Some melted cosmic spherules produce refractory nuggets during atmospheric entry (Brownlee et al., 1984; Rudraswami et al., 2014). The spherules that are ablation products of meteorites, although rare, can be distinguished generally by their major element ratios, however, if they undergo severe heating and ablation during atmospheric entry then they develop glassy textures and would be indistinguishable from cosmic spherules from other sources (Genge and Grady, 1999). The unmelted particles provide direct evidence for types of meteorites that they were a part of (van Ginneken et al., 2012; Suavet et al., 2011), such information is difficult to ascertain from most cosmic spherules. The exception to this rule is scoriaceous micrometeorites, which, in view of their matrix dominant textures can be equated with $\mathrm{Cl}$ carbonaceous chondrite type parent body (Kurat et al., 1994; Engrand and Maurette, 1998; Maurette et al., 2000) A majority of micrometeorites in this genre have chemical compositions that enable their identification as being parts of $\mathrm{Cl}$ or $\mathrm{CM}$ chondrites (Brownlee et al. 1997) with smaller percentages of other meteorite types in the total flux (Taylor et al., 2007). However, the larger meteorites show a reverse trend, where, the ordinary chondrites dominate the flux with $87 \%$ and the carbonaceous chondrites comprise a miniscule $\sim 3 \%$ percent of the meteorite flux (Krot et al., 2003). More recently, micrometeorites that have an ordinary chondrite (van Ginneken et al. 2012; Suavet et al., 2010; 
Genge, 2008 ) or achondritic (Cordier et al. 2011) provenance have been identified. These findings indicate more widespread sources for the cosmic materials that rain onto the Earth in the form of dust.

Relict grains in melted micrometeorites provide strong evidence for pinpointing the parent meteorite types. Blanchard et al. (1980) reported $\sim 10 \%$ of the cosmic spherules they observed contained relict grains that were mostly zoned olivines having Mg-rich cores; the other relict minerals identified were ferrous spinel, chromite and pentlandite. Beckerling and Bischoff (1995) carried out detailed investigations on the relict grains in micrometeorites from the polar regions, olivines and pyroxenes dominated the relict grains in addition to perovskite, chromite, Fe-Ni metal etc. They suggested carbonaceous chondritic precursors for a majority of the relict grain-bearing particles, a few could also be from ordinary chondrites and none from achondrites or mesosiderites. However, subsequent investigations (e.g., Badjukov et al., 2010; Gounelle et al., 2009; Delaney et al., 2004) identified achondritic micrometeorites. Further, Taylor et al. (2011) reported that relict olivines and pyroxenes dominated among the relict grain bearing particles, however, they also identified feldspars and spinel some of which helped identify achondritic particles among their collection. Imae et al. (2013) analyzed olivines and pyroxenes from micrometeorites and compared them with those found in meteorites, their results showed a majority of the micrometeorites are from carbonaceous chondritic source, however, they report $22 \%$ of the micrometeorites have an ordinary chondrite precursor, more probably an unequilibrated ordinary chondrite. There have not been many investigations on chromites in micrometeorites or on dusty olivines. Parashar et al. (2011) identified an unequilibrated ordinary chondritic parent body for a chromite-bearing micrometeorite in their collection. We analyzed 481 melted micrometeorites from the Indian Ocean isolated from ten close-spaced surficial sediment samples (Prasad et al. 2013), in this collection several relict grains were found such as forsterite (dominant), pentlandite, troilite, chromites and reversely-zoned olivines. While forsterites and sulfurbearing minerals have been commonly identified among all such collections and have been attributed a $\mathrm{Cl}$ or CM chondritic parent source (eg Taylor et al. 2011), the chromites and reversely-zoned olivines that contain small blebs of metal, which are otherwise known as 'dusty olivines', can be directly linked to ordinary chondritic parent bodies of different metamorphic grades. In the present study, we present our investigations on chromites and 'dusty olivines' found in melted micrometeorites from the Indian Ocean.

\section{SAMPLING AND ANALYSES}

The spherules were isolated from ten deep seafloor sediment samples covering a total surface area of $2.5 \mathrm{~m}^{2}$, the details of sampling and spherule isolation techniques employed are described in Prasad et al. (2013). Out of the 481 spherules that were examined relict grain bearing and scoriaceous 
spherules together constitute $8.5 \%$. Chemical composition of the spherules was determined with a CAMECA SX-5 Electron Probe Microanalyser at the National Institute of Oceanography and CAMECA SX-100 at Physical Research Laboratory, Ahmedabad. Silicate and oxide standards were used for all the analyses at an acceleration voltage of $15 \mathrm{kV}$, a beam current of $12 \mathrm{nA}$ and beam diameter of 2 $\mu \mathrm{m}$ especially when analyzing the relict grains, whereas for bulk analyses the beam diameter was 10 $\mu \mathrm{m}$. Several spots on each spherule or feature were obtained to arrive at average compositions. The data reduction and correction was done using PAP model (Pouchou and Pichoir, 1991).

The laser ablation inductively coupled plasma mass spectrometer (LA-ICP-MS) at National Geophysical Research Institute (CSIR-NGRI, Hyderabad) was used for high precision situ analyses of trace elements in micrometeorites. Seven spherules were chosen for this analysis : 3 spherules with chromite grains, 3 with dusty olivines (out of which two spherules comprising wholly of dusty olivine grains) and an additional spherule which had both dusty olivine and chromite as relict grains. The ablation was done using New Wave UP $213 \mathrm{Nd}$ :YAG laser with beam size of $\sim 60$ um with a repetition rate of $10 \mathrm{HZ}$ that provides an energy of $\sim 3-6 \mathrm{~mJ}$. The analyses generates a pit of size $\sim 40 \mathrm{um}$. The above parameter is the same for all the spherules analyzed in this work. Laser was coupled to Thermo $X$ Seriesll Quadrupole. The analyses also included $45 \mathrm{~s}$ gas blank background before the start of the analyses. The ablation was done for $85 \mathrm{~s}$ with dwell time of $\sim 20 \mathrm{~ms}$ for each analysis. The details on the analyses is also provided in Rudraswami et al. (2012). SRM 612 was used for bracketing the error. For every 5-10 samples analyses, the SRM 612 was used for bracketing using 2 analyses before and after the unknown analyses. USGS BCR-2G and BHVO-2G was also included during the set of analyses to verify the data in between the analyses. Internal calibration is done using Ca for the quantitative analyses. The sets of standards were repeated multiple times to verify the precision of the data sets before and after the analyses. The data are processed using Glitter software. The standard errors in a majority of the trace elements have ranges from $\sim 10-20 \%$, but in some elements can go as high as $\sim 30 \%$. The Glitter software calculated the detection limits for individual measurements in each run using Poisson counting statistics (refer http://gemoc.mq.edu.au/AnMethods/AnlyticalMeth.html\#3 for more details).

\section{DESCRIPTION OF MICROMETEORITES}

This study focuses on relict grain-bearing spherules especially those with dusty olivines or chromites. The most prominent relict grains observed are forsterites whether they are in a fine-grained matrix or in porphyritic spherules, they are followed by Fe-Ni-S minerals such as troilite and pentlandite, we have not come across pyroxene grains in this collection although we found glassy spherules having bulk compositions which are pyroxene normative (Rudraswami et al., 2012). In all, 7 spherules are 
observed to contain chromites, 7 spherules are observed to contain 'dusty' reverse zoned olivine grains . Three spherules contain both chromites and dusty olivines. One spherule has a cluster of olivines and pyroxenes and in a glassy matrix and appears to be a relict of a porphyritic olivine - pyroxene (POP) chondrule. All the spherules are in the diameter range of $173-430 \mu \mathrm{m}$, however only two spherules are the extreme ends of the size range, all the others are close to the average diameter in this collection $(265 \mu \mathrm{m})$ (Prasad et al., 2013)(Table 1).

\section{CHROMITE-BEARING SPHERULES}

Seven spherules are found to enclose chromite grains (Table 1). Five of them have one chromite grain in the cross section observed, however, two spherules have more than one : AAS38-155\#1-P6 contains 10 chromite grains, the largest of which is $\sim 80 \mu \mathrm{m}$ (Fig. $1 \mathrm{~A}, \mathrm{~B}$ ), and AAS38-178\#1-P3 has two chromite grains, respectively (Fig. 1E,F).

The spherules that contain chromites have a diameter range of 230-443 $\mu \mathrm{m}$ (majority of them between $230-300 \mu \mathrm{m})$. Out of the seven spherules that enclose chromites five have a criss-cross barred texture with the grey areas in between the bars having higher Si and Al contents than the bars. Of the other two spherules, one is a glassy spherule and the other is a relict-grained spherule with a dusty olivine inclusion. The spherules are not barred in the conventional sense, i.e., the normal barred spherules have olivine lathes arranged in parallel orientations with the interstitial areas occupied by glass and magnetite grains. Here the bars are criss-cross and magnetites are absent. The light coloured (BSE image ) area comprises of higher $\mathrm{Ca}, \mathrm{Fe}, \mathrm{Al}$ and $\mathrm{Si}$ contents. The glassy portions between olivine laths in barred spherules were also described as containing $\mathrm{Ca}, \mathrm{Fe}, \mathrm{Al}$, Si glass by Blanchard et al. (1980).

The presence of chromite (melting temperature is $\sim 2000^{\circ} \mathrm{C}:$ Greenwood and Earnshaw ,1997) implies the spherules have not reached this temperature during atmospheric entry. One chromite-bearing spherule has a troilite inclusion. The presence of FeS is an indication that this spherule was not severely heated during entry, sulfide survival sets an upper limit to the temperature experienced by this spherule. The same spherule has a small chromite inclusion (Fig. 1C,D) which is partly resorbed into the melt.

Jackson (1969) identified the relative compositions of olivine and chromite in a given rock provide valuable insights into the formation temperatures. Therefore the $\mathrm{Fe} /(\mathrm{Fe}+\mathrm{Mg})$ of olivine vs $\mathrm{Cr} /(\mathrm{Cr}+\mathrm{Al})$ of chromites has been traditionally used as a formation temperature indicator for meteorites for over the last few decades (Bunch et al., 1967). In our case, the chromites are mostly found in spherules which have undergone melting during atmospheric entry and the olivine grains equilibrated in the spherule as 
barred olivines, therefore it is not possible to compare chromite composition with that of olivine in cosmic spherules. Further, chromite has a narrow compositional range within chondrites, and it is uniform in each chondrite (Schnetzinger et al., 1967). Extensive analyses of chromites in meteorites have confirmed that chromites in meteorites in view of their narrow and characteristic compositions with different chondrites can be used to classify meteorites (Bunch and Olsen, 1975). Over a period of time, Birger Schmitz and his group (Schmitz et al., 2001; 2003; Schmitz and Haggstrom, 2006 and Alwmark and Schmitz 2009) have systematically analyzed several hundred chromites from fossil meteorites which helped identify the type and sub-types of the fossil ordinary chondrites discovered by them. This aspect once again emphasizes the diagnostic importance of chromites in identifying and classifying ordinary chondrites.

In the present investigation, seventeen chromite grains from 7 spherules have been analyzed, their


are presented in Fig. 5 . It is observed that the chromite data from the literature presented in Fig. 5 define characteristic areas for different meteorite groups/sub-groups of ordinary chondrites in these plots. Major oxide ratios (bulk compositions) of the chromite-bearing spherules are also plotted to help decipher their provenance(Figs. 6).

There are seven spherules that enclose chromites, with AAS38-155\#1-P6 containing 10 chromites (Fig. 1A,B), out of which 6 could be analyzed with the microprobe.

All chromites (but one) in this spherule show similar compositions (Table 2), confirming the observation (Bunch and Olsen, 1975) that chromites from individual chondrites have similar compositions, therefore highlighting their diagnostic value. The chromites from this spherule plot along with the chromites from the high metamorphic grade chondrites, they plot close to L5, L6 and H5 chondrites in all the oxide plots (Figs. 5,6). The high Ti contents of the chromites strongly suggest an L5 or L6 parent body. The TiO2 contents of ordinary chondrites shows an increasing trend from $H$ to $L$ to $L L$ and also from increasing metamorphic grades from 3-6 (Alwmark and Schmitz, 2009). A similar trend is seen in the chromite enclosed in the spherule AAS38-165\#III-P32 in view of its Ti content (Table 2) where the $\mathrm{Ti} / \mathrm{Cr}$ and $\mathrm{Ti} / \mathrm{Al}$ ratios fall close to $\mathrm{L} 6$ chondrites (Figs. 5,6). However, this spherule also contains a dusty olivine inclusion and the $\mathrm{Al} / \mathrm{Cr}$ ratios fall close to $\mathrm{H} 3$ chondrites.

It is also seen from the literature (Bunch et al., 1967; Wlotzka, 2005) that the chromites from unequilibrated chondrites have low $\mathrm{TiO}_{2}$ and low vanadium contents as well and they plot in the extreme lower and left of the plot of $\mathrm{V}_{2} \mathrm{O}_{5}$ vs $\mathrm{TiO}_{2}$ (Fig. 5). We find there are at least three chromites from three different spherules that plot close in this area. One of them (AAS63-54-P10) contains a large troilite inclusion (Fig. 1C,D) and the chromite is diffuse and small and appears to be mostly 
equilibrated with the melt. Two chromites are observed in AAS38-178\#1-P3 (Fig 1E, F). Both of these chromites plot in two extremes of the V vs Ti plot (Fig.5). One chromite plots close to the L3 chromite area of the plot and the other plots in the extreme right side of the diagram. However, both these chromites are at the rim of the spherule and seafloor etching, in addition to entry heating, could have altered their compositions. However, the larger of the two chromites for which we were able to obtain relatively reliable analysis plots close to the L3 area of the $\mathrm{V}$ vs Ti plot. Therefore, it can assumed that this particular spherule could be a part of an unequilibrated chondrite, as does AAS6354-P10, which contains troilite.

The spherule AAS38-165-\#III-P32 has a dusty olivine relict grain and a diffuse chromite (Fig. 2 C). In view of its high Ti contents (Table2), the Ti/Cr and Ti/Al ratios plot in the area of L6 chromites, however, the $\mathrm{Al} / \mathrm{Cr}$ ratios plot close to $\mathrm{H} 3$ chondrites.

The chromite in the spherule AAS38-178\#2-P16 (Fig. 1F from Rudraswami et al., 2012) is the only one found in a spherule with a barred texture with parallel olivine lathes. The chromite is large in size $(\sim 50 \mu \mathrm{m})$ and the $\mathrm{Al}$ contents of this chromite are the lowest in this collection. The chromite grain margins appear to be rounding and undergoing resorption into the melt, therefore one cannot be certain of the chemical alteration undergone atmospheric entry. This chromite also plots close to chromites in L4 chondrites Ti vs Al plot. In the V vs Al plots close to L4 chromite area, and in the Ti/Cr plot it again falls close to L4 chromites.

Beckerling and Bischoff (1995) carried out detailed investigations on relict grains in over 200 micrometeorites from polar regions (Greenland and Antarctica), 66 of them having relict grains. They identified 140 forsterite grains either in fine-grained or porphyritic micrometeorites and pyroxenes next in abundance (84 relict pyroxenes). The other relict grains identified by them are perovskite, chromite, $\mathrm{Fe}, \mathrm{Ni}$-metal, magnetite, and sulfides. The chromites identified by them are small in size and present in spherules having Fa-rich olivine relict grains (similar to the dusty olivine grains as shown in the present study) and the presence of chromite in a pyroxene normative mesostasis was reported by them. In addition they also reported partly resorbed chromite-bearing relict olivines in a fine-grained to glassy groundmass. However, the chromites analyzed by them had Mn contents up to $9 \mathrm{wt} \%$ similar to those found in $\mathrm{Cl}$ chondrites (Endre $\beta$ and Bischoff, 1993). We did not observe any chromite with enhanced $\mathrm{Mn}$ contents. More importantly, the $\mathrm{Al}_{2} \mathrm{O}_{3}$ concentrations of all the chromites (Table 2) are in the range


contents of chromites in carbonaceous chondrites are much higher, up to $15-16 \mathrm{wt} \%$ (Brearley and Jones, 1998). 
In summary, two spherules show strong indications for an L6 parent body (AAS38-155\#1-P6 and AAS38-153II\#1-P9; Table 2 ). The chromite composition of four spherules agrees with an L3 or H3 parent body (Table 2). One spherule (AAS-38-165-\#III-P32) enclosing a dusty olivine inclusion (Fig. 2C) shows mixed signals. It has high Ti content typical of high metamorphic grade ordinary chondrites, however, the $\mathrm{Al} / \mathrm{Cr}$ ratios of the chromite in this spherule indicate a $\mathrm{H} 3$ parent body, the dusty olivine inclusion also supports an unequilibrated chondrite. The major elemental ratios (atomic) normalised to $\mathrm{Cl}$ chondrites of a majority of the spherules, especially their $\mathrm{Mg} / \mathrm{Si} / \mathrm{Cl}, \mathrm{Al} / \mathrm{Si} / \mathrm{Cl}$ and $\mathrm{Ti} / \mathrm{Si} / \mathrm{Cl}$ ratios, are close to those of ordinary chondrites (Fig. 6).

\section{Parent bodies of chromite bearing spherules}

Chromite is a common trace mineral in ordinary chondrites at $0.5-5$ vol\%, and it is rare or absent in carbonaceous and enstatite chondrites as well as iron meteorites (Ramdohr, 1967; Rubin 1997). Out of the seven spherules that contain chromites two of them show a strong indication of an L6 parent body, four spherules indicate unequilibrated chondrites ( $\mathrm{L} 3$ or H3) as parent bodies and one spherule having a dusty olivine inclusion indicates either an L6 ( in view of high Ti contents) or H3 parent body in view of $\mathrm{Al} / \mathrm{Cr}$ ratios and presence of a dusty olivine inclusion. Overall, the spherules appear to be derived from two different types of ordinary chondritic parent bodies.

In chondrites, chromite occurs in two main forms : Interstitial grains in the matrix and as xenomorphic grains against silicates and show idiomorphic shapes only (Wlotzka, 2005). Most of the chromites in the present investigation appear to be idiomorphic in shapes, some of which appear to be in the process of undergoing melting and resorption during entry. As per the observation of Wlotzka (2005) the spherules that contain the chromites could be part of ordinary chondritic matrix.

Chondrite-normalized major element bulk composition of the spherules that contain chromites show $\mathrm{Mg} / \mathrm{Si}, \mathrm{Al} / \mathrm{Si}$, and Ti/Si ratios conforming to those of $\mathrm{L}$ and $\mathrm{H}$ chondrites (Fig. 6). Fe/Si shows depletion, probably because Fe being a relatively volatile element it could have been depleted during atmospheric entry. However, the $\mathrm{Ca} / \mathrm{Si}$ also shows depletion with respect to chondrite-normalized ratios. Brownlee et al. (1997) suggested a CM-like parent body for most cosmic spherules; however, they also suggested that the chemical compositions of those belonging to ordinary chondrites could be distinguished based on their major element ratios. Most of the major element ratios (e.g., Mg/Si, Fe/Si and $\mathrm{Ca} / \mathrm{Si}$ ) indicate their affinity towards $\mathrm{L}$ and $\mathrm{H}$ chondrites.

\section{DUSTY OLIVINE SPHERULES}

Seven spherules are observed to enclose dusty olivines. Two of these are porphyritic and comprise entirely of dusty olivine grains in a glassy matrix (Fig.3 A, B), four spherules contain dusty olivine 
inclusions and have textures which are criss-cross barred (one of which is a RGB in a fine-grained matrix) (e.g., Fig. 3 C,D), and one spherule has half of the olivines reversely zoned and contain small blebs of almost pure Fe (Fig. 3E, F,G) and the other half of the olivines are normally zoned (i.e., with a Mg-rich core and a Fe-rich rim). This is reverse of the zoned olivines commonly observed in the porphyritic spherules and the olivine observed in the scoriaceous and RGB spherules - where the interior is forsteritic and the exterior is more fayalitic. All the spherules conform to the description of dusty olivines as proposed by several investigators (Rambaldi and Wasson,1982; Jones and Danielson, 1997; Hewins, 1997), in the sense the olivines show a reverse zoning with an Fe-rich core and an Mg-rich rim and contain small blebs of almost pure metal or sometimes chrome-spinel inclusions.

Out of the two spherules that comprise entirely of dusty olivine grains (Fig. $3 \mathrm{~A}, \mathrm{~B}$ ), there are several common features : both have euhedral reversely zoned olivines, that enclose chrome-spinel grains, in a glassy matrix. The olivines in both the spherules show vast differences in their core and rim compositions with $\mathrm{Fa}$ contents in the cores of zoned olivine grains reaching $\geq 30$ mole\% (Table 3 ). However, the zoning is more pronounced in AAS-38-155-P2, out of 5 olivine grains that were analyzed with the EPMA the Fo contents in these grains range from 54 to 75 mole\%. In addition, one euhedral Fe-rich olivine grain (Fa 69.91) is seen as an inclusion and the largest olivine grain in this spherule is close to $100 \mu \mathrm{m}$ in its longest dimension and encloses a vug-like feature comprising of enstatite pyroxene grains (Fig. 3A).

All investigations suggest dusty olivine formation in a reducing environment (e.g., Fox and Hewins, 2005); therefore, the presence of an Fe-rich olivine (hortonolite composition) close to that of a fayalite could imply that the fayalitic grain was incorporated after the formation of the spherule, because fayalite is known to form under oxidizing conditions.

One spherule shows approximately half of the olivines which are dusty in appearance and the rest of the olivines show normal zoning (Fig .3 F, G). The dusty olivines in this porphyritic spherule contain several large blebs of almost pure Fe (Fig. 3G). Another relict grain-bearing spherule contains a very large reversely zoned olivine $(140 \mu \mathrm{m})$ in size and several other similarly zoned smaller olivines in a glassy matrix (Fig. 3H).

Four spherules have dusty olivines as inclusions in a matrix which has a criss-crossed texture similar to the one described for the chromite-bearing spherules in this study (e.g., Fig.3 C, D). The matrix has $\mathrm{Ca}, \mathrm{Fe}, \mathrm{Al}, \mathrm{Si}$ glassy composition and the darker 'bar' portions have an olivine normative composition. Magnetite, which is common for all conventional barred cosmic spherules, is once again conspicuous by its absence in these spherules. 
There have been observations of dusty olivines in micrometeorites. Taylor et al., (2011) presented spherules having similar relict reversely zoned olivines. Beckerling and Bischoff (1995) identified several such olivine-bearing spherules where the Fa mole\% was observed to be dominantly between 12-30 mole\% with a rare few greater than 30 mole\%. However, Brownlee et al. (1983) report on a scoriaceous spherule which encloses a relict forsterite which contains bright (dusty) metals that were devoid of nickel, they suggested that the metal formed due to reduction of silicates and/or the decomposition of sulfide in a carbonaceous chondritic parent body.

\section{Origin of Dusty Olivine bearing spherules}

Dusty olivines were first reported to contain Ni-poor nanometer-sized metal inclusions (Rambaldi, 1981; Rambaldi and Wasson, 1982 ; Nagahara, 1981). They were suggested to be solid state alteration products of a previous generation of chondrules due to the in situ reduction of Fe from the host olivines (Rambaldi and Wasson, 1982; Hewins, 1983; Jones and Danielson, 1997; Rubin, 2006). Therefore, dusty olivines have a role in understanding chondrule recycling (Ruzicka et al., 2007). Dusty olivine grains within chondritic meteorites have been proposed as suitable candidates for retaining a faithful memory of pre-accretionary magnetic fields [Uehara and Nakamura, 2006; Lappe et al., 2011). Dynamic crystallization experiments confirm that dusty olivine can be produced by reduction of FeOrich olivine in unequilibrated ordinary chondrite (UOC) material (Lofgren and Le 2002; Hewins, 2003; Uehara and Nakamura, 2006). The reduction that formed the Fe-Ni inclusions is thought to be caused by the presence of organic or graphitic carbon in the chondrule precursor (Connolly et al., 1994). It requires low oxygen fugacity (below the Fe-wüstite buffer) and temperatures between 950 and $1500^{\circ} \mathrm{C}$ (Boland and Duba, 1981). Pack et al. (2003) observed orthoenstatite as by-product of this reaction. This perhaps explains the presence of pyroxene enclosed in one of the large dusty olivine grains in AAS-38-155-P2 (Fig. 1A). Semarkona, an L3 chondrite has chondrules that range in size from a few $\mathrm{mm}$ to microchondrules measuring $<10 \mu \mathrm{m}$ in diameter (Hutchison et al., 1987) therefore the present range in diameter of the dusty olivine bearing spherules comes well within this range in terms of size.

Pyroxene crystals similar to those observed in the vug-like feature in AAS38-155-P2 (Fig. 3A) are observed in dusty olivine bearing chondrules of UOCs. Olivine occurring as chadacrysts inside pyroxene grains in chondrules of ordinary chondrites (L3, Semarkona) have been reported (Jones, 1996). In addition to dusty metal in chondrules, Rambaldi and Wasson (1982) also observed minor orthopyroxene and $\mathrm{Ca}$, Al-rich glass within the chondrules. Boland and Duba (1981) produced Nipoor, pure Fe crystals in the interiors of olivines by experimentally heating olivine under reducing conditions, in addition they also observed pyroxene or $\mathrm{SiO}_{2}$. Rubin (2006) observed a porphyritic olivine 
chondrule in Semarkona (LL3.0) that contained numerous dusty olivines, some of them enclosing lowCa-pyroxene similar to the one enclosed in AAS39-155-P2 (Fig. 3A).

Cosmic spherules or chondrules (?)

Dusty olivines can be found in ordinary chondrites, CM2, CV3, and CO3 chondrites, but always in type 3 chondritic meteorites (Kracher et al., 1984). Dusty olivine grains have been observed in chondrules, more commonly in those of unequilibrated ordinary chondrites such as Semarkona, Chainpur, Inman, Ragland etc. (Jones and Danielson, 1997), and also rarely as isolated grains in the matrices (Kracher et al., 1983). Kracher et al. (1984) describe porphyritic olivine chondrules that consist almost entirely of dusty olivines (e.g., St. Mary's County LL 3.3 meteorite), the authors describe no other meteorite containing such chondrules that comprise entirely of dusty olivines. In the present investigation, two such spherules are found : AAS38-155-P2 (this spherule also contains a fayalite inclusion, and a large hopper dusty olivine that encloses pyroxene crystals); The low-Ca pyroxene poikilitically enclosed in a dusty olivine AAS-38-155-P2 suggests that the pyroxene also crystallized in situ. AAS38-178-\#2-P2 (most of the dusty olivines in this spherule contain chrome-spinel inclusions). All the olivines in these two spherules show a decrease in $\mathrm{Fe} /(\mathrm{Fe}+\mathrm{Mg})$ ratio toward the borders of the grains, which according to Kracher et al. (1984) takes place when a chondrule reacts with a reducing gas. These two spherules appear to be chondrules and were apparently heated to temperatures not much above the solidus, because the presence of a fayalitic grain in one of them indicates a heating which is not greater than its crystallization temperature of $1205^{\circ} \mathrm{C}$ (Deer et al., 1992). Or the fayalitic grain could have been captured subsequent to the formation of the spherule.

However, simulation experiments have indicated a minimum temperature of $1250^{\circ} \mathrm{C}$ would be needed in order to form the scoriaceous textured cosmic spherules. Spherules that display porphyritic, barred or glassy textures would have undergone greater temperatures during entry (Fox and Hewins, 2005). The presence of a fayalitic grain in AAS-38-155-P2 (Fig.3A) suggests that this spherule has survived atmospheric entry without attaining such temperature. The spherules are devoid of a rim of FeO rich material which is commonly seen on spherules. Such a rim is indicative and heating and oxidation during atmospheric entry, the absence of the magnetite rim also indicates that these two spherules have not undergone significant melting during entry.

These chondrules could have been reduced during crystallization, so that the FeO does not show normal zoning. This observation of Kracher et al. (1984) appears to be relevant especially for the above porphyritic spherules which comprise entirely of dusty olivine grains. In addition, most dusty olivine grains in both these spherules contain chrome-spinel inclusions. 
It appears that the two porphyritic spherules that comprise wholly of dusty olivines (AAS38-155-P2 and AAS38-178-\#2-P2) can qualify as chondrules and as for the others, similarity in composition and in appearance (e.g., Fig. 3C,D,E,F,G) between the dusty olivines and the matrix in at least 4 spherules suggests that they are all of the same origin - these could have been chondrules altered during atmospheric entry with a few dusty olivine grains that still remained unoxidized, probably because the temperatures attained during entry were not sufficiently high. In only one spherule, a large dusty olivine inclusion in a cryptocrystalline/glassy matrix (Fig. $3 \mathrm{H}$ ) suggests that this grain is a relict and could have been part of a matrix or a chondrule.

\section{POP CHONDRULE-LIKE SPHERULE}

Van Ginneken et al. (2012) identified unmelted particles from Transantarctic Mountains which have a granoblastic texture of olivine and enstatite, which they identified as POP chondrule-like materials. One spherule in this collection could belong to this category : AAS38-186-P8 -REMSPH (Fig. 4A,B). This spherule has grains that comprise an equal mixture of olivine and pyroxene therefore, it is similar to porphyritic olivine pyroxene chondrule-like materials in a glassy matrix (Fig. 4A,B). The olivine and pyroxene crystals are sub-hedral and appear to be partly resorbed. The pyroxene is Ca-poor and is enstatitic in composition. This spherule could be a POP chondrule of Type II.

Porphyritic chondrules contain abundant, relatively large (up to one half of the chondrule diameter) fairly uniformly sized crystals in a fine-grained of glassy mesostasis. Porphyritic chondrules that are dominated by olivine (>10/1 volume ratio) are referred to as porphyritic olivine chondrules (Gooding and Keil, 1981). Porphyritic chondrules happen to be olivine-rich (PO) or pyroxene-rich (PP) or pyroxene-olivine-rich (POP) with 5-10\% of normative feldspar. POP chondrules are much rarer (Hutchison, 2004 ). Porphyritic, pyroxene-and olivine-rich (POP) chondrules and porphyritic, pyroxenerich (PP) chondrules constitute approximately $50 \mathrm{vol} \%$ and $10 \mathrm{vol} \%$ of all chondrules in ordinary chondrites, respectively (Gooding and Keil, 1981; Jones, 1994).

\section{Trace element compositions}

Seven spherules were analyzed for trace elements (Table 5; Fig. 7), three out of which contain chromites, three others contain dusty olivines and one spherule contains chromite and dusty olivine inclusions. Two spherules show UOC characteristics e.g., AAS38-155-1-P2, AAS38-178-2-P2. Both of these spherules comprise wholly of dusty olivines and are suggested here to belong to UOC parent source (by way of chromite composition or presence of dusty olivines ) : the Rb and Zn contents do not show as much depletions as do those that show characteristics of L5- or L6 chondrites (e.g., AAS38153-II-P9 and AAS38-155-1-P6 (Fig.7). 
Wang and Lipschutz (2007) suggested a consistency in the trace elemental compositions of all UOCs $(\mathrm{H}, \mathrm{L}$ or $\mathrm{LL})$, and except for the highly volatile elements such as $\mathrm{Cd}, \mathrm{Bi}$ and $\mathrm{TI}$. $\mathrm{Rb}$ in their analysis shows a narrow range (Cl-normalized) with not much depletion with respect to $\mathrm{Cl}$ for UOCs. Anders and Zadnik (1985) suggested the contents of the volatile traces in ordinary chondrites decreases with increase in metamorphic type. In contrast, the bulk contents of refractory elements remain remarkably uniform for all chondrite metamorphic types (Ebihara et al., 1996).

Micrometeorite internal texture has been identified as qualitative indicator of the amount of heating undergone during atmospheric entry (Taylor et al. 2000). Simulation experiments have substantiated these observations (Toppani and Libourel 2003). If we consider the above, the textures of the chromite-bearing spherules (at least 4-5 of them) are similar, whereas their chromite chemistry indicates different sub-groups of ordinary chondrites. Their volatile trace elements $(\mathrm{Rb}, \mathrm{ZN}, \mathrm{Pb})$ also show complimentary differences. Strong depletion of $\mathrm{Ba}, \mathrm{Rb}, \mathrm{Zn}$, and $\mathrm{Pb}$ are seen for the two spherules which indicate an L5/L6 parent body (AAS38-153-II-P9 and AAS38-155-I-P6), whereas for the other spherules for which $\mathrm{f}$ parameters such as chromite composition, presence of dusty olivines etc. show an UOC parent linkage, the depletion of the volatiles is not that strong (Fig. 7).

Th, $\mathrm{U}$ and Ba show enhancements which reach 10X of $\mathrm{Cl}$ values in some spherules (Fig.7). These spherules had long residence times on the deep seafloor which could be up to 50,000 years (Prasad et al., 2013). Pattan et al. (2005), Pattan and Jauhari (2001) measured trace elements from the sediments in this part of the Indian Ocean. The sediments here contain Th=11-12 ppm; U=1-1.5 ppm and $\mathrm{Ba}=3000-4000$ ppm. In contrast chondrites have Th, and $U$ at ppb levels, and $\mathrm{Ba}$ is a few ppm (Mason, 1971) which are several orders of magnitude less. Therefore, the enhancements in Th, $U$, and $\mathrm{Ba}$ contents of the spherules appear to be due to incorporation of these elements from terrestrial sources.

\section{DISCUSSION AND CONCLUSIONS}

Most investigations on micrometeorites involving large numbers of particles have proposed a dominance of carbonaceous chondritic material in the particulate flux on the Earth which is $\mathrm{CM}$ or $\mathrm{Cl}$ chondrite (Brownlee, 1997; Prasad et al., 2013). Genge and Grady (2002) proposed 70\% contribution from carbonaceous chondrites and 30\% from an ordinary chondritic source; whereas Taylor et al.(2000) supported this division, but suggested a small (1-2\%) contribution from iron meteorites and an even smaller contribution $(0.5 \%)$ from achondrites. This contrasts with the meteorite flux where ordinary chondrites (87\%) dominate the flux on the Earth (Krot et al., 2003). This difference is attributed to physical properties of the carbonaceous chondrites which tend to fragment much easily during asteroidal collisions and produce larger quantities of dust-sized materials (Flynn, 1989). Besides 
fragmentation in space, atmospheric breakup plays a major role in determining what types of materials can survive atmospheric entry to make micrometeorites. Revelstoke and Tagish Lake are excellent examples of materials that were almost entirely disrupted into dust and vapor during entry. However, in more recent investigations, ordinary chondritic materials have been observed to comprise at least 33\% of the large-sized (>500 $\mu \mathrm{m}$ ) particles (Suavet et al., 2010; 2011; van Ginneken et al., 2012). Genge (2008) suggests a substantial contribution from ordinary chondrites $(\sim 20 \%)$ to the micrometeorite flux.

In addition, meteorites comprise of chondrules, matrix, AOAs and CAls. In contrast, matrix-dominant materials dominate the micrometeorite populations where, it is observed that at least $25 \%$ of most major unbiased collections comprise of scoriaceous materials which have a provenance of $\mathrm{Cl}$ chondritic parent bodies (Taylor et al., 2000; Prasad et al., 2013). However, among the unmelted populations of micrometeorites, the parent bodies of many materials could be ascribed with greater certainty and among these populations ordinary chondrites (e.g., Genge, 2008), achondritic materials and even fragments containing chondrules have been observed (Gounelle et al., 2009; van Ginneken et al., 2012). It has been possible to identify chondrules among the melted micrometeorite populations, recently Imae et al. (2013) identified four CO3 chondrules. We have recently attempted to do so using oxygen isotopes (Rudraswami et al., 2014 submitted). In the present investigation, perhaps for the first time, we find a strong evidence for ordinary chondritic parent sources among the spherules and also possible chondrules from unequilibrated ordinary chondrites. An individual chondrule enclosed in a cosmic spherule has been identified earlier (Reshma et al. 2013 ), but that has been an isolated occurrence.

In the present study, 7 spherules with chromites and 7 spherules with dusty olivines and one POP spherule are presented. Their morphologies, major element compositions, trace element compositions, and more importantly, chromite composition enables us to identify them to be of ordinary chondritic provenance. These constitute 15 out of 481 spherules investigated and comprise only $\sim 3 \%$ of the total number of spherules. Prasad et al. (2013) investigated all the 481 spherules in this collection and observed a majority of the spherules had undergone alteration during atmospheric entry which was revealed in their textures such as barred, cryptocrystalline and glassy; however, based on their major element ratios these spherules could be identified as chondritic and possibly either $\mathrm{Cl}$ or $\mathrm{CM}$. In addition, they also found $8.5 \%$ of these spherules to be of scoriaceous in texture and could have had $\mathrm{Cl}$ chondritic parent sources. The I-type and G-type spherules together constituted an additional 8.5\% which during their recent investigations using the PGE contents of FeNi beads Rudraswami et al. (2013, 2014) could identify a chondritic parent source. Prasad et al. (2013) further identified one spherule in this collection to be achondritic. It is possible there could be a larger number of particles 
with ordinary chondritic provenance, however, due to the alteration undergone during atmospheric entry they are not recognizable. While all the 15 particles in this investigation appear to be from ordinary chondrites, their chromite composition allows us to make the distinction that at least one of which (AAS38-155-\#1-P6; Fig .1 A,B) could be from an L5 or L6 chondrite, and at least two of the dusty olivine bearing particles (Fig. 3A,B) appear to be chondrules from an unequilibrated ordinary chondrite. In view of the large volumes occupied by chondrules in ordinary chondrites, there should be many more chondrules from ordinary chondritic source among the micrometeorite flux.

\section{ACKNOWLEDGEMENTS}

The authors are grateful to the Director, NIO for the encouragement and the facilities. MSP, NGR and AAR are grateful to PRL, Ahmedabad for the PLANEX project on micrometeorites and to the CSIR XIIth Plan project GEOSINKS. EVSSKB and TVK are grateful to the Director NGRI, Hyderabad for the facilities. They further acknowledge financial support through MLP-6513-28-EVB and PSC-0204 (INDEX)-WP-2.1 project grants. We acknowledge with gratitude the help rendered by Vijay Khedekar and Samena Balgar during the analyses and sample preparation respectively. We are grateful to an anonymous reviewer for the comments and suggestions; and, Christian Koeberl and Don Brownlee for the detailed, painstaking reviews and suggestions which helped improve the manuscript considerably. The samples were collected during the cruises for the project : Surveys for Polymetallic Nodules (PMN) by one of us (MSP), thus we thank the Ministry of Earth Sciences for the funding of the PMN Project.

\section{REFERENCES}

Alwmark C. and Schmitz B. 2009 The origin of the Brunflo fossil meteorite and extraterrestrial chromite in mid-Ordovician limestone from the Gärde quarry (Jämtland, central Sweden). Meteoritics and Planetary Science 44: 95-106

Anders E. and Grevesse N. 1989. Abundances of the elements -meteoritic and solar. Geochimica et Cosmochimica Acta 53, 197-214.

Anders E. and Zadnik M.G. 1985. Unequilibrated ordinary chondrites: A tentative subclassification based on volatile-element content. Geochimica et Cosmochimica Acta 49 : 1281-1291.

Badjukov D. D., Brandstätter F., Raitala J. and Kurat G. 2010. Basaltic micrometeorites from the Novaya Zemlya glacier. Meteoritics and Planetary Science 45: 1502-1512.

Beckering W. and Bischoff A. 1995. Occurrence and composition of relict minerals in micrometeorites from Greenland and Antarctica-implications for their origins. Planetary and Space Science 43, 435449. 
Blanchard M. B., Brownlee D. E., Bunch T. E., Hodge P. W., and Kyte F. T. 1980. Meteoroid ablation spheres from deep-sea sediments. Earth and Planetary Science Letters 46:178-190.

Boland, J. N., A. Dube. 1981. Solid-state reduction of iron in olivine - Planetary and meteoritic evolution. Nature 294: 142-144.

Brearley A. J. and Jones R. H. 1998. Chondritic meteorites Chapter 3. In Planetary Materials, (ed. J. J. Papike), pp.1-398. Reviews in Mineralogy. Vol 36, Mineralogical Society of America, Washington, DC.

Brownlee D. E. 1985. Cosmic dust: Collection and research. Annual Review of Earth and Planetary Sciences 13:147-173.

Brownlee D. E., Bates B., and Beauchamp R. H. 1983. Meteor ablation spherules as chondrule analogs. In Chondrules and their origin, edited by King E. A. Houston, Texas: Lunar and Planetary Institute. pp. 10-25.

Brownlee D. E., Bates B. A., and Wheelock M. M. 1984. Extraterrestrial platinum group nuggets in deep-sea sediments. Nature 309:693-695.

Brownlee D. E., Bates B. and Schramm L. 1997. The elemental composition of stony cosmic spherules. Meteoritics and Planetary Science 32, 157-175.

Bunch T.E. and Olsen E. 1975 Distribution and significance of chromium in meteorites. Geochimica et Cosmochimica Acta 39: 911-927

Bunch T. E., Keil K., and Snetsinger K. G. 1967. Chromite composition in relation to chemistry and texture of ordinary chondrites. Geochimica et Cosmochimica Acta 31:1569-1582.

Connolly H. C. Jr., Hewins R. H., Ash R. D., Zanda B., Lofgren G. E., and Bourot-Denise M. 1994. Carbon and the formation of reduced chondrules: An experimental investigation. Nature 371:136-139.

Cremonese G., Borin P., Martellato E., Marzari F. and Bruno M. 2012. New calibration of the micrometeoroid flux on Earth. The Astrophysical Journal Letters 749, L40 (4pp).

Deer W. A., Howie R. A. and Zussman J. 1992 An Introduction to the Rock-forming Minerals (2nd ed.). Longman Scientific, New York, pp. 696.

Delaney J. J., Herzog G.F. and Taylor S. 2004. Crumbs from the crust of Vesta : Achondritic micrometorites from the south pole water well. Lunar and Planetary Science XXXV, Abstract \# 1895.

Ebihara M., Shinotsuka K. and Kong P. 1996. Redistribution of trace elements during metamorphism of ordinary chondrites. Abstracts, $27^{\text {th }}$ Lunar and Planetary Science Conference, 329-330.

Endress M. and Bischoff, A. 1993. Mineralogy, degree of brecciation, and aqueous alteration of $\mathrm{Cl}$ chondrites Orgeuil, Ivuna, and Alais. Meteoritics $28: 345-346$.

Engrand C. and Maurette M. 1998. Carbonaceous micrometeorites from Antarctica. Meteoritics and Planetary Science 33 ; 565-580.

Fox G.E. and Hewins R.H. 2005. Chondrule reheating experiments and relict olivine. Geochimica et Cosmochimica Acta 69: 2441-2449 
Flynn, G. J. 1989. Atmospheric entry heating: a criterion to distinguish between asteroidal and cometary sources of interplanetary dust. Icarus 77, 287-310.

Genge M. J. and Grady M. M. 1999. The fusion crusts of stony meteorites : Implications for the atmospheric reprocessing of extraterrestrial materials. Meteoritics and Planetary Science 34: 341-356.

Genge M. J. and Grady M. M. 2002. The distribution of asteroids: Evidence from Antarctic micrometeorites (abstract \#1010). 33rd Lunar and Planetary Science Conference. CD-ROM.

Genge M. J. 2008. Koronis asteroid dust within Antarctic ice. Geology 36 : 687-690.

Genge M. J., Engrand C., Gounelle M., and Taylor S. 2008. The classificaiton of micrometeorites. Meteoritics \& Planetary Science 43:497-515.

Gooding J. L. and Keil K. 1981. Relative abundances of chondrule primary textural types in ordinary chondrites and their bearing on conditions of chondrule formation. Meteoritics 16:17-43.

Gounelle M., Chaussidon M., Morbidelli A., Barrat J., Engrand C., Zolensky M.E. and Kevin D. McKeegan K.D. 2009. A unique basaltic micrometeorite expands the inventory of solar system planetary crusts. Proceedings of the National Academy of Sciences 106:6904-6909.

Greenwood N.N. and Earnshaw A. 1997. Chemistry of the Elements, 2nd ed., Butterworth-Heinemann, Oxford, UK. 1341 pp.

Häggström T. and Schmitz B. 2007. Distribution of extraterrestrial chromite in Middle Ordovician Komstad Limestone in the Killeröd quarry, Scania, Sweden. Bulletin of the Geological Society of Denmark 55:37-58.

Hewins R. H. 1983. Dynamic crystallization experiments as constraints on chondrule genesis. In Chondrules and their origins (A85-26528 11-91),edited by King E.A. Houston, Texas : Lunar and Planetary Institute. pp. 122-133.

Hutchison R., Alexander C. M. O'D., and Barber D. J. 1987. The Semarkona meteorite: First recorded occurrence of smectite in an ordinary chondrite and its implications. Geochimica et Cosmochimica Acta 51:1875-1882.

Hewins R.H. 1997. Chondrules. Annual Reviews Earth and Planetary Sciences. 25:61-83

Hutchison R. 2004. Meteorites. A Petrologic, Chemical and Isotopic Synthesis. Cambridge University Press, 506 pp..

Imae N., Susan Taylor S. and Iwata N. 2013. Micrometeorite precursors: Clues from the mineralogy and petrology of their relict minerals. Geochimica et Cosmochimica Acta 100:116-157

Jackson E. D. 1969. Chemical variation in coexisting chromite and olivine in chromitite zones of the Stillwater Complex. Economic Geology, Monograph $4,41-71$.

Jones R. H. 1996. Relict grains in chondrules: evidence for chondrule recycling. In Chondrules and the Protoplanetary Disk, edited by. R. H. Hewins, R. H. Jones and E. R. D.Scott. Cambridge University Press, Cambridge, pp. 163-172. 
Jones R. H. and Danielson L. R. 1997. A chondrule origin for dusty relict olivine in unequilibrated chondrites. Meteoritics and Planetary Science 32, 753-760.

Kracher A., Scott E.R.D. and Keil K. 1983. Dusty olivines in the Vigarano (CV3) chondrite : Evidence for an ubiquitous reduction process. Abstracts, $14^{\text {th }}$ Lunar and Planetary Science Conference, LPI,Houston 407-408.

Kracher A., Scott E. R. D., and Keil K. 1984. Relict and other anomalous grains in chondrules: Implications for chondrule formation. Abstracts 14th Lunar and Planetary Science Conference, LPI, Houston B559-B566.

Krot A. N., Keil K., Goodrich C. A., Scott E. R. D. and Weisberg M. K. 2003. Classification of meteorites. In meteorites, comets, and planets. In Treatise on Geochemistry, vol. 1 (ed. A. M.Davis). Elsevier Pergamon, Amsterdam, pp. 83-128.

Kurat G., Koeberl C., Presper T., Brandstätter F. and Maurette M. 1994. Petrology and geochemistry of Antarctic micrometeorites. Geochimica et Cosmochimica Acta 58 : 3879-3904.

Lappe S.C.L.L., Harrison R.J. and Feinberg J.M. 2012. Rock magnetic properties of dusty olivine: a potential carrier of pre-accretionary remanence in unequilibrated ordinary chondrites. Geophysical Research Abstracts 14, EGU2012-11211.

Love S. G. and Brownlee D. E. 1993. A direct measurement of the terrestrial mass accretion rate of cosmic dust. Science 262:550-553.

Mason B. 1971. Handbook of elemental abundances in meteorites. Gordon and Breach, 555 pp.

Maurette M., Olinger C., Christophe Michel-Levy M., Kurat G., Pourchet M., Brandsta" tter F., and Bourot-Denise M. 1991. A collection of diverse micrometeorites recovered from 100 tonnes of Antarctic blue ice. Nature 351:44-47.

Maurette M., Duprat J., Engrand C., Gounelle M., Kurat G., Matrajt G. and Toppani A. 2000. Accretion of neon, organics, $\mathrm{CO} 2$, nitrogen and water from large interplanetary dust particles on the early Earth. Planetary and Space science 48: 1117-1137.

Nagahara H. 1981. Evidence for secondary origin of chondrules. Nature 292:135-136.

Nehru C. E., Weisberg M. K. and Prinz M. 1997. Chromites in unequilibrated ordinary chondrites. Lunar and Planetary Science Conference XXVIII. \#1651.

Pack A. and Palme H. 2003. Partitioning of $\mathrm{Ca}$ and $\mathrm{Al}$ between forsterite and silicate melt in dynamic systems with implications for the origin of $\mathrm{Ca}$, Al-rich forsterites in primitive meteorites. Meteoritics \& Planetary Science 38:1263-1281.

Parashar K., Shyam Prasad M., and Chauhan S. S. 2010. Investigations on a large collection of cosmic dust from the Central Indian Ocean. Earth, Moon, and Planets, 107:197-217.

Pattan J.N., Pearce N.J.G. and Mislankar P.G. 2005. Constraints in using Cerium-anomaly of bulk sediments as an indicator of paleo bottom water redox environment : A case study from the Central Indian Ocean Basin. Chemical Geology 221 : 260-278. 
Pattan J.N. and Jauhari P. 2001. Major, trace and rare earth elements in the sediments of Central Indian Ocean Basin : Their source and distribution. Marine Georesources and Geotechnology 19 : 85106.

Peucker-Ehrenbrink B. and Ravizza G. 2000. The effects of sampling artifacts on cosmic dust flux estimates: A reevaluation of nonvolatile tracers (Os, Ir). Geochimica et Cosmochimica Acta 64:19651970.

Pouchou J. L. and Pichoir F. 1991. Quantitative analysis of homogeneous or stratified microvolumes applying the model "PAP." In Electron probe quantification, edited by Heinrich K. F. J. and Newbury D. E. New York: Plenum Press. pp. 31-75.

Prasad M. S., Rudraswami N. G. and Panda D. K. 2013. Micrometeorite flux on Earth

during the last $\sim 50,000$ years. Journal of Geophysical Research.118, 2381-2399.

Rambaldi E. R. 1981. Relict grains in chondrules. Nature 293:558-561.

Rambaldi $\mathrm{R}$ and Wasson J.T. 1982. Fine, nickel-poor Fe-Ni grains in the olivine of unequilibrated ordinary chondrites. Geochimica et Cosmochimica Acta 46: 929-939.

Ramdohr P. 1967. Chromite and chromite chondrules in meteorites-I. Geochimica et Cosmochimica Acta 81: 1961-1967

Reshma K., Rudraswami N.G. and Prasad M.S. 2013. Chondrule-like object from the Indian Ocean cosmic spherules. Journal of Earth System Science 122, 1161-1171.

Rubin A. E. 1997. Mineralogy of meteorite groups. Meteoritics and Planetary Science 32:231-247.

Rubin A.E. 2006. A relict-grain-bearing porphyritic olivine compound chondrule

from LL3.0 Semarkona that experienced limited remelting. Meteoritics and Planetary Science. 41: 1027-1038.

Rudraswami N. G., Parashar K. and Shyam Prasad M. 2011. Micrometer and nanometer size platinum group nuggets in micrometeorites from the deep sea sediments of Indian

Ocean. Meteoritics and Planetary Science 46, 470-491.

Rudraswami N. G., Shyam Prasad M., Babu E. V. S. S. K., Vijaya Kumar T., Feng W. and

Plane J.M.C. 2012. Fractionation and fragmentation of glass cosmic spherules during atmospheric entry. Geochimica et Cosmochimica Acta 99, 110-127.

Rudraswami N. G., Prasad S. M., Plane J. M. C., Berg T., Feng W. and Balgar S. 2014.

Refractory metal nuggets in different types of cosmic spherules. Geochimica et Cosmochimica Acta 131, 247-266. 
Rudraswami N.G. ; Prasad M.S., Nagashima K. and Jones R.H. 2014. Oxygen isotopic composition of relict olivine grains in micrometeorites: Links to chondrules from carbonaceous chondrites. Geochimica et Cosmochimica Acta (submitted)

Schmitz B., Tassinari M., and Peucker-Ehrenbrink B. 2001. A rain of ordinary chondrites in the early Ordovician. Earth and Planetary Science Letters 194:1-15.

Schmitz B., Häggström T., and Tassinari M. 2003. Sediment dispersed extraterrestrial chromite traces a major asteroid disruption event. Science 300:961-964.

Schmitz B. and Häggström T. 2006. Extraterrestrial chromite in Middle Ordovician limestone at Kinnekulle, southern Sweden- Traces of a major asteroid breakup event. Meteoritics \& Planetary Science 41:455-466.

Schmitz B., Harper D. A. T., Peucker-Ehrenbrink B., Stouge S., Alwmark C., Cronholm A., Bergström S. M., Tassinari M., and Xiaofeng W. 2008. Asteroid breakup linked to the Great Ordovician Biodiversification Event. Nature Geoscience 1:49-53.

Snetsinger K. G., Keil K. and Bunch T. E. 1967 Chromite from "equilibrated" chondrites. American Mineralogist 52, 1322-1331.

Suavet C., Alexandre A., Franchi I. A., Gattacceca J., Sonzogni C., Greenwood R. C., Folco

L. and Rochette P. 2010. Identification of the parent bodies of micrometeorites with

high-precision oxygen isotope ratios. Earth and Planetary Science Letters 293 : 313-320.

Suavet, C., Cordier C., Rochette P. Folco L., Gattacceca J., Sonzogni C. and Damphoffer D. 2011. Ordinary chondrite-related giant $(>800 \mu \mathrm{m})$ cosmic spherules from the Transantarctic Mountains Antarctica, Geochimica et Cosmochimica Acta 75:6200-6210.

Taylor S. and Brownlee D.E. 1991. Cosmic spherules in the geologic record. Meteoritics 26 : 203-211

Taylor S., Lever J., and Harvey R. 2000. Numbers, types and compositional distribution of an unbiased collection of cosmic spherules. Meteoritics and Planetary Science 35:651-666.

Taylor S., Herzog G. F., and Delaney J. S. 2007. Crumbs from the crust of Vesta: Achondritic cosmic spherules from the South Pole water well. Meteoritics and Planetary Science 42:223-233.

Taylor S., Matrajt G.and Guan Y. 2011. Fine-grained precursors dominate the micrometeorite flux. Meteoritics and Planetary Science 47: 550-564

Toppani A., Libourel G., Engrand C. and Maurette M. 2001. Experimental simulation of atmospheric entry of micrometeorites. Meteoritics and Planetary Science 36 : 1377-1396.

Toppani A. and Libourel G. 2003. Factors controlling compositions of cosmic spinels: application to atmospheric entry conditions of meteoritic materials. Geochimica et Cosmochimica Acta 67, 46214638. 
Uehara M. and Nakamura N. 2006. Experimental constraints on magnetic stability of chondrules and the paleomagnetic significance of dusty olivines. Earth and Planetary Science Letters 250:292-305.

Van Ginneken, M., Folco L., Cordier C. and Rochette P. 2012. Chondritic micrometeorites

from the Transantarctic Mountains, Meteoritics and Planetary Science 47, 228-247.

Wang M-S and Lipschutz M.E. 2007. Trace elements in primitive meteorites-II Antarctic unequilibrated ordinary chondrites. Geochimica et Cosmochimica Acta 71:1062-1073.

Wasson J. T. and Kallemeyn G. W. 1988. Compositions of chondrites. Philosophical Transactions of the Royal Society of London. A 325, 535-544.

Wlotzka F. 2005. Cr spinel and chromite as petrogenetic indicators in ordinary chondrites: Equilibration temperatures of petrologic types 3.7 to 6. Meteoritics \& Planetary Science 40:1673-1702.

Yada T., Nakamura T., Takaoka N., Noguchi T., Terada K., Yano H., Nakazawa T. and

Kojima H. 2004. The global accretion rate of extraterrestrial materials in the last glacial period estimated from the abundance of micrometeorites in Antarctic glacier ice. Earth, Planets and Space 56, 67-79. 


\section{FIGURE LEGENDS}

\section{FIGURE 1:}

A : Image of a polished section of spherule showing numerous chromites, three large vesicles are also seen which could have been made by the escaping volatile elements during atmospheric entry. Note the criss-cross texture of the spherule.

B : Chromite grains shown in (A) under higher magnification, at least ten chromite grains can be seen having different sizes. The light grey areas in between the criss-cross patterns are enhanced in $\mathrm{Ca}, \mathrm{Al}$, and Si contents. This is observed consistently in all chromite-bearing spherules.

C : Image of a spherule containing a small, rounded chromite (in the circle), a large vesicle comprising partly of troilite is also seen. Criss-cross texture is also observable in this spherule.

D : Image of chromite shown in (C) magnified. This chromite appears to have been resorbed partly into the spherule, troilite grains can be seen at the top right corner of the image.

E : Image of a spherule containing two chromite grains (at the bottom). Similar criss-cross texture is seen in the spherule as in the earlier spherules.

$F$ : Arrows point towards the two chromite grains shown in $(E)$ under higher magnification.

G : Image of a spherule with large vesicles and a chromite which is partly resorbed. The criss-cross pattern is persistent in this spherule as well.

$\mathrm{H}$ : The chromite shown in $\mathrm{G}$ magnified, it has become sub-hedral due to melting and heating.

All the images shown in Figure 1 are SEM backscattered electron images (BSE).

\section{FIGURE 2 :}

A and B: BSE image of a spherule with a large vesicle (making it appear crescent-shaped), a small chromite is seen at the top right edge of the spherule, which is magnified in (B).

C : BSE image of a spherule showing a large dusty olivine relict grain and a partly resorbed chromite. A large vacuole is seen in this spherule as well. It is discernible that the other olivines are zoned 'normally' in a glassy matrix in the rest of the spherule. The vacuoles have been made by the volatile elements which expanded because of heating experienced during atmospheric entry.

\section{FIGURE 3 :}

A : Porphyritic spherule comprising entirely of dusty olivine grains in a glassy matrix. Arrow points towards a sub-hedral fayalitic grain is seen in the spherule (Fa). Another arrow points towards a vuglike feature containing pyroxenes (px) enclosed by the largest dusty olivine grain. 
B : Another porphyritic spherule comprising entirely of dusty olivines. The individual bright spots in many grains are chrome-spinel. In addition, small bright areas are metal in the grains. Reverse-zoning (Fe-rich interior and Mg-rich rim) is seen in all the grains.

C : Image of a relict grain-bearing spherule with two dusty olivine grains, in a criss-cross pattern background.

D : Dusty olivine relict grain shown in (C) under higher magnification. Reverse zoning and numerous small blebs of metal are discernible. .

E : Porphyritic spherule comprising partly of dusty olivines and the others are normally zoned olivines.

F : Magnified image of dusty olivine grains with metal blebs and the glassy matrix is also visible.

G : Pure Fe metal contained in one of the dusty olivine grains shown in $(F)$ under high magnification.

$\mathrm{H}$ : Relict grain bearing spherule containing a large dusty olivine inclusion and few other small reversely zoned grains. The matrix is partly glassy and is also sulfur-rich in the top left of the image.

All the images shown in Figure 3 are SEM backscattered electron images (BSE).

\section{FIGURE 4 :}

A : BSE image of a porphyritic olivine pyroxene (POP) spherule. A cluster of olivines and pyroxenes are seen in the center of the spherule in a glassy matrix. The mineral grains appear to be partly resorbed in the matrix.

$\mathrm{B}$ : The olivine and pyroxene cluster magnified ( $\mathrm{PX}=$ pyroxene; OL=olivine) the olivine is forsteritic and the pyroxene is mostly enstatite (data presented in Table 4).

FIGURE 5 : Oxide ratios of chromites in the present study compared with those in ordinary chondrites. Chromite data for ordinary chondrites from Bunch et al. (1967), and Wlotzka, (2005).

FIGURE 6 : $\mathrm{Cl}$ normalized (atom) major element ratios (bulk composition) of the spherules $(n=15)$ in this study. The areas where bulk compositions of $L$ and $H$ chondrites occur are flagged. $H$, and $L$ chondrite averages from Wasson \& Kallemeyn (1988).

FIGURE 7 : Cl chondrite normalized trace element compositions of micrometeorites ( $\mathrm{Cl}$ chondrite values from Anders and Grevesse, 1989). The data is presented in the order of increasing volatility from left to right. 

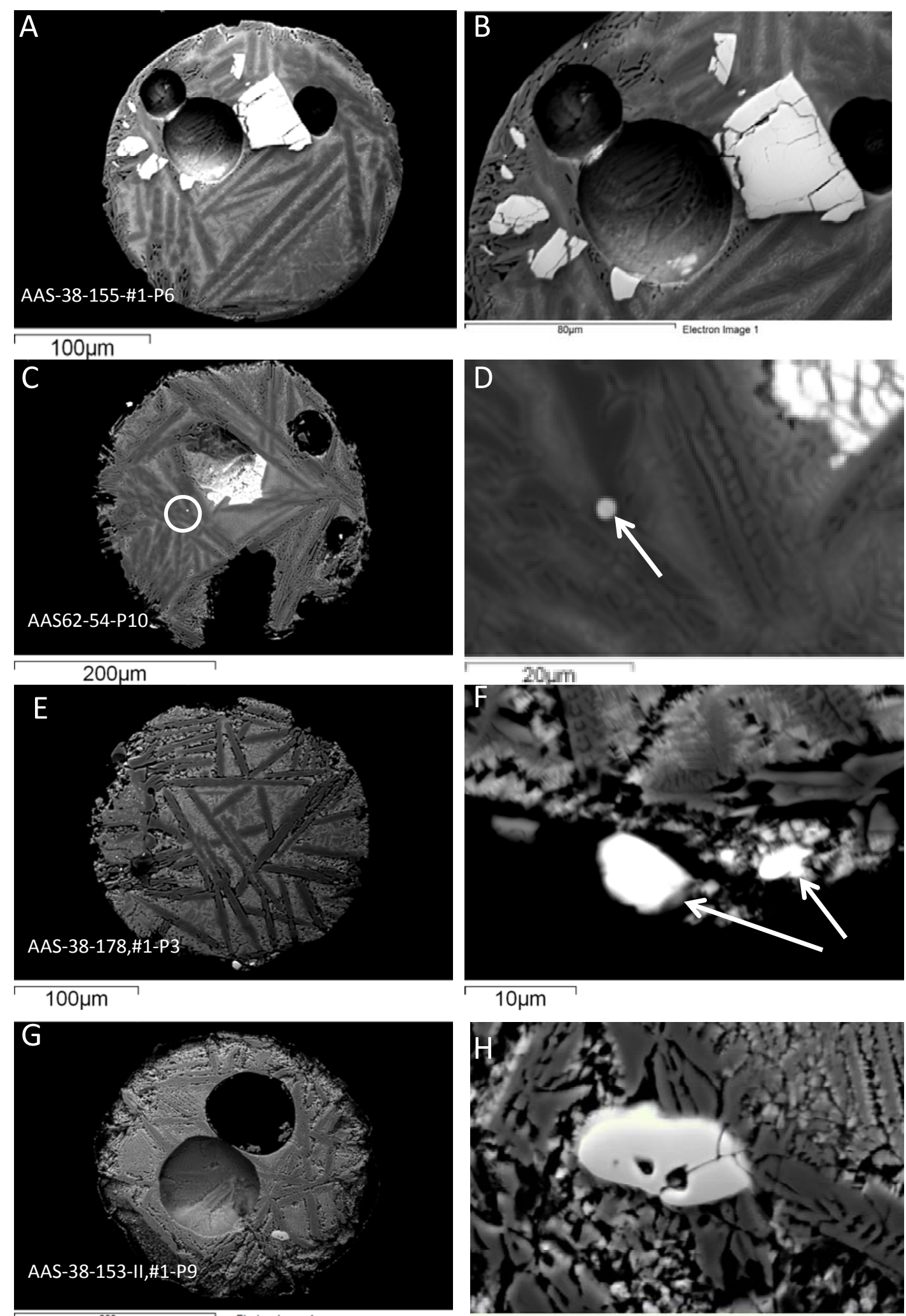

Fig. 1

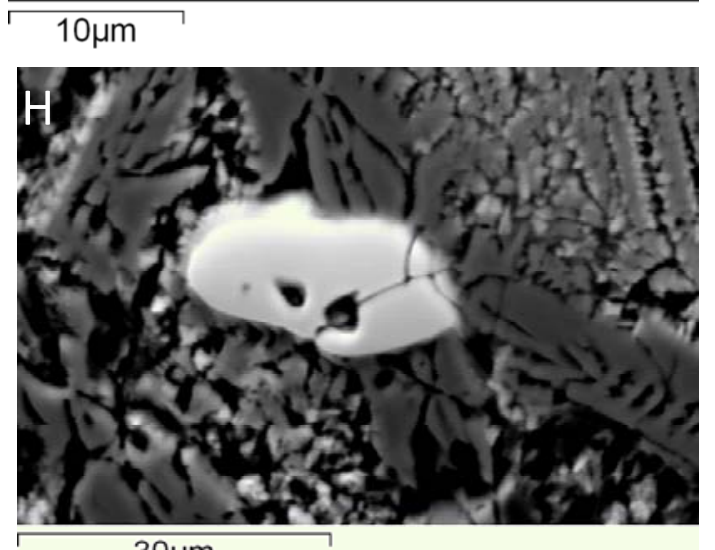

$$
30 \mu \mathrm{m}
$$



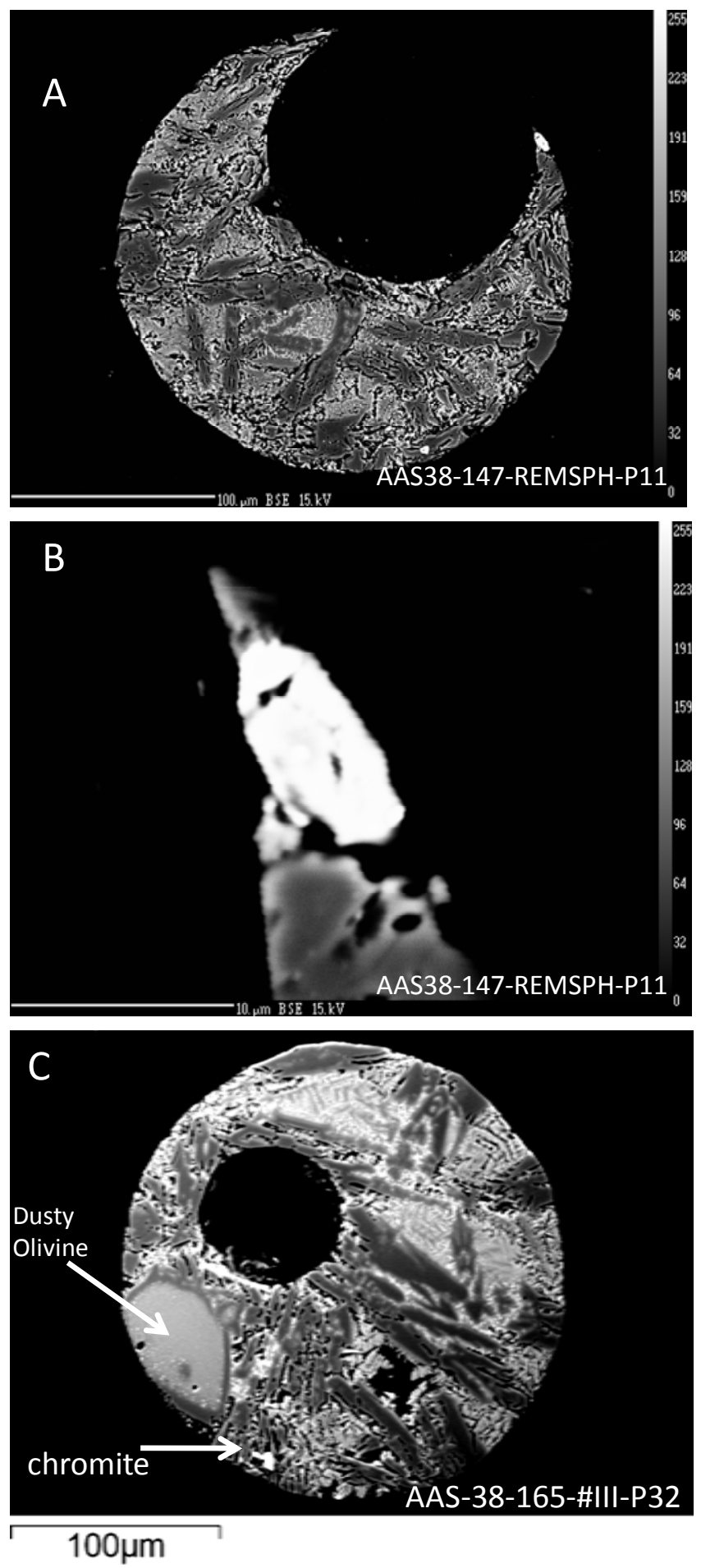

Fig. 2 

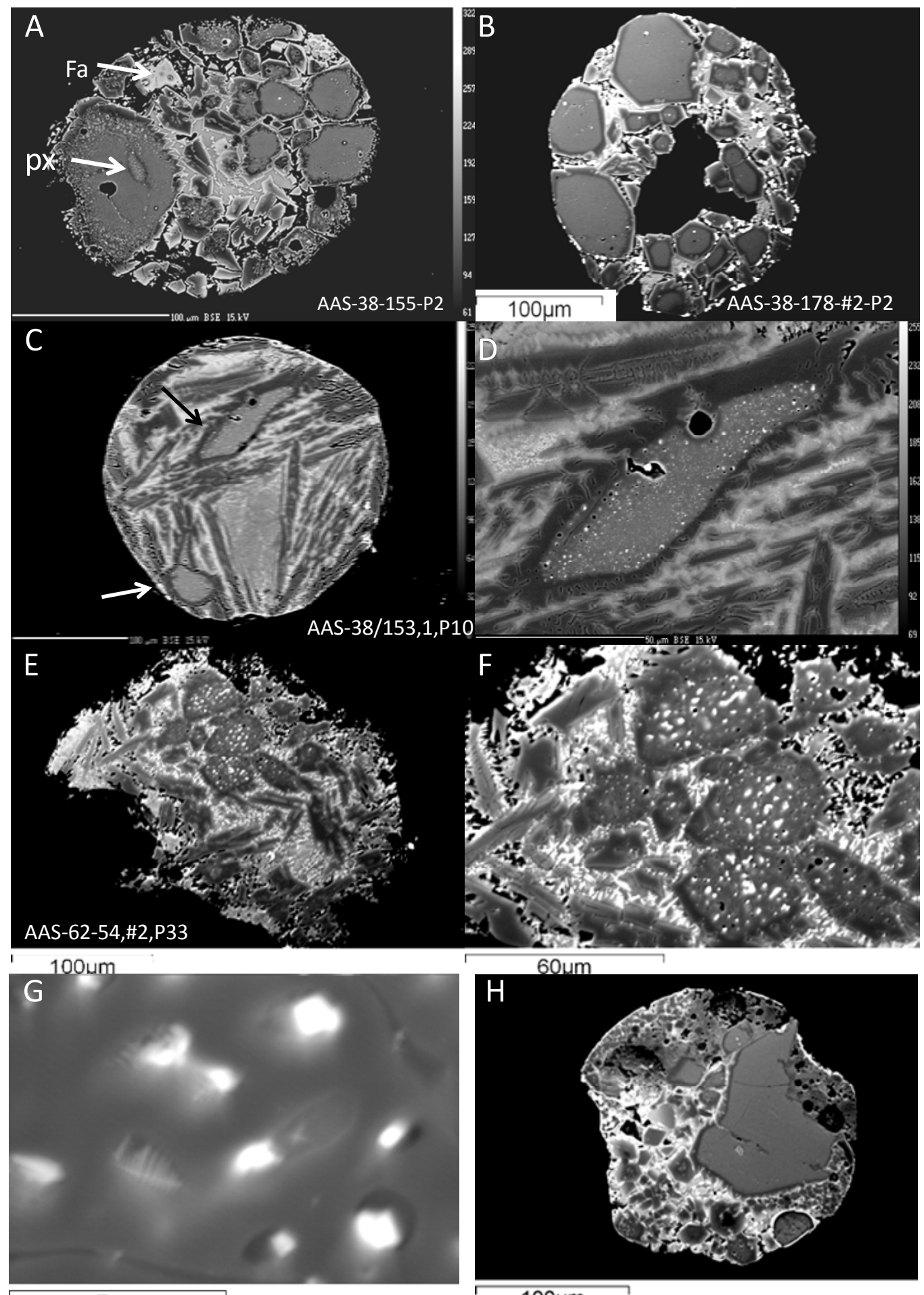

60um

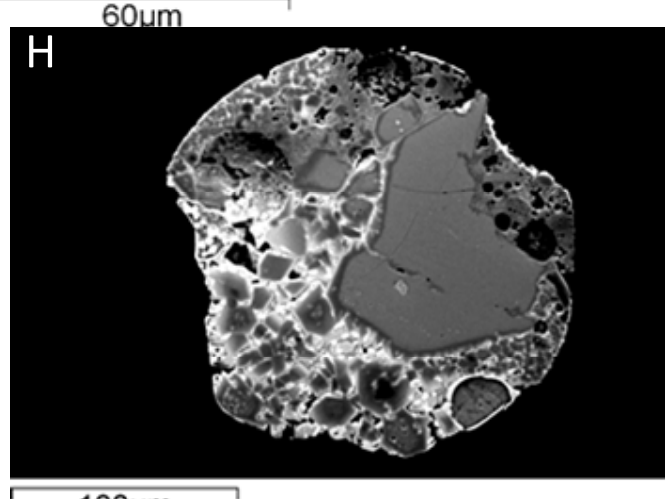

Fig.3 


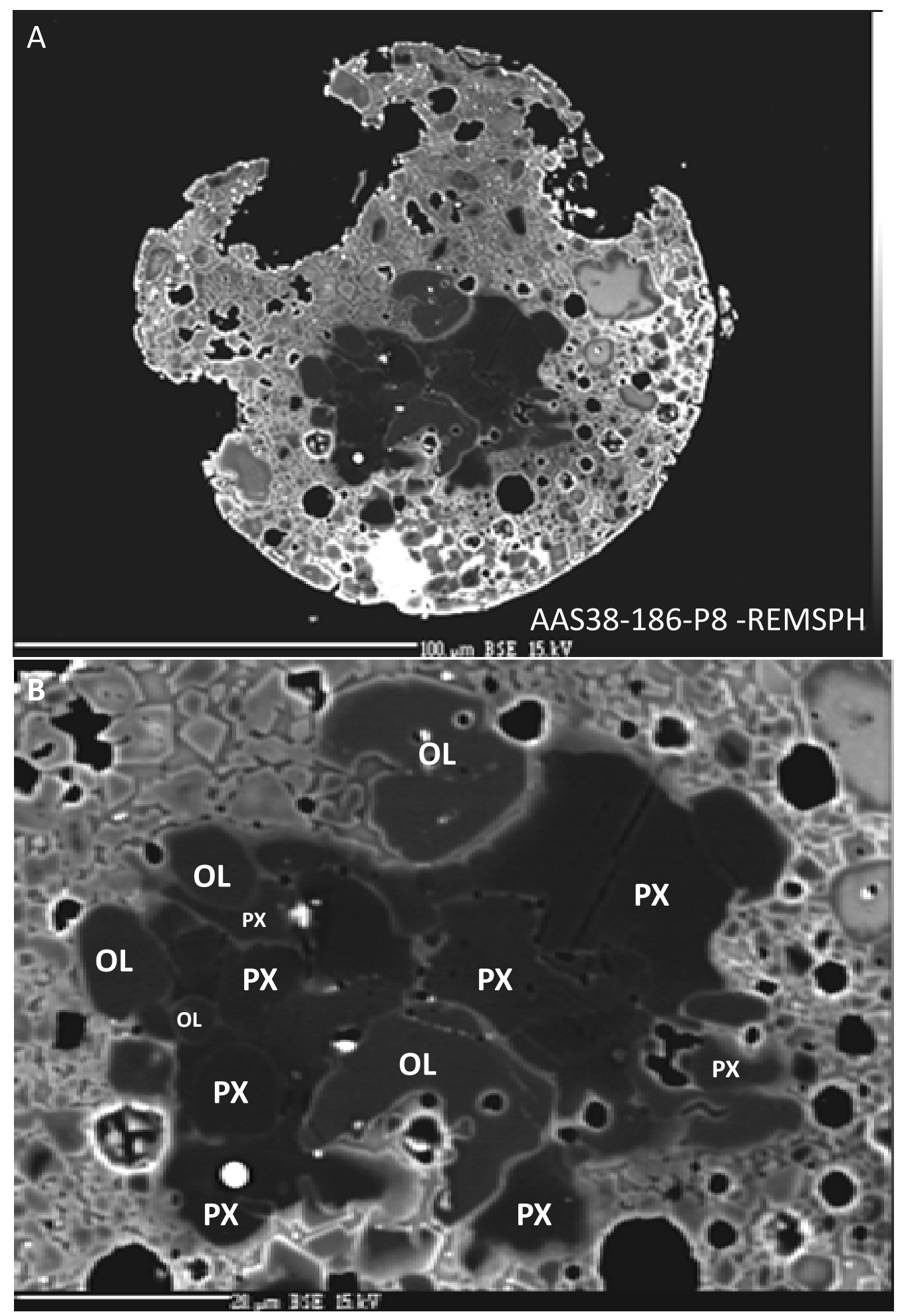

Fig.4 

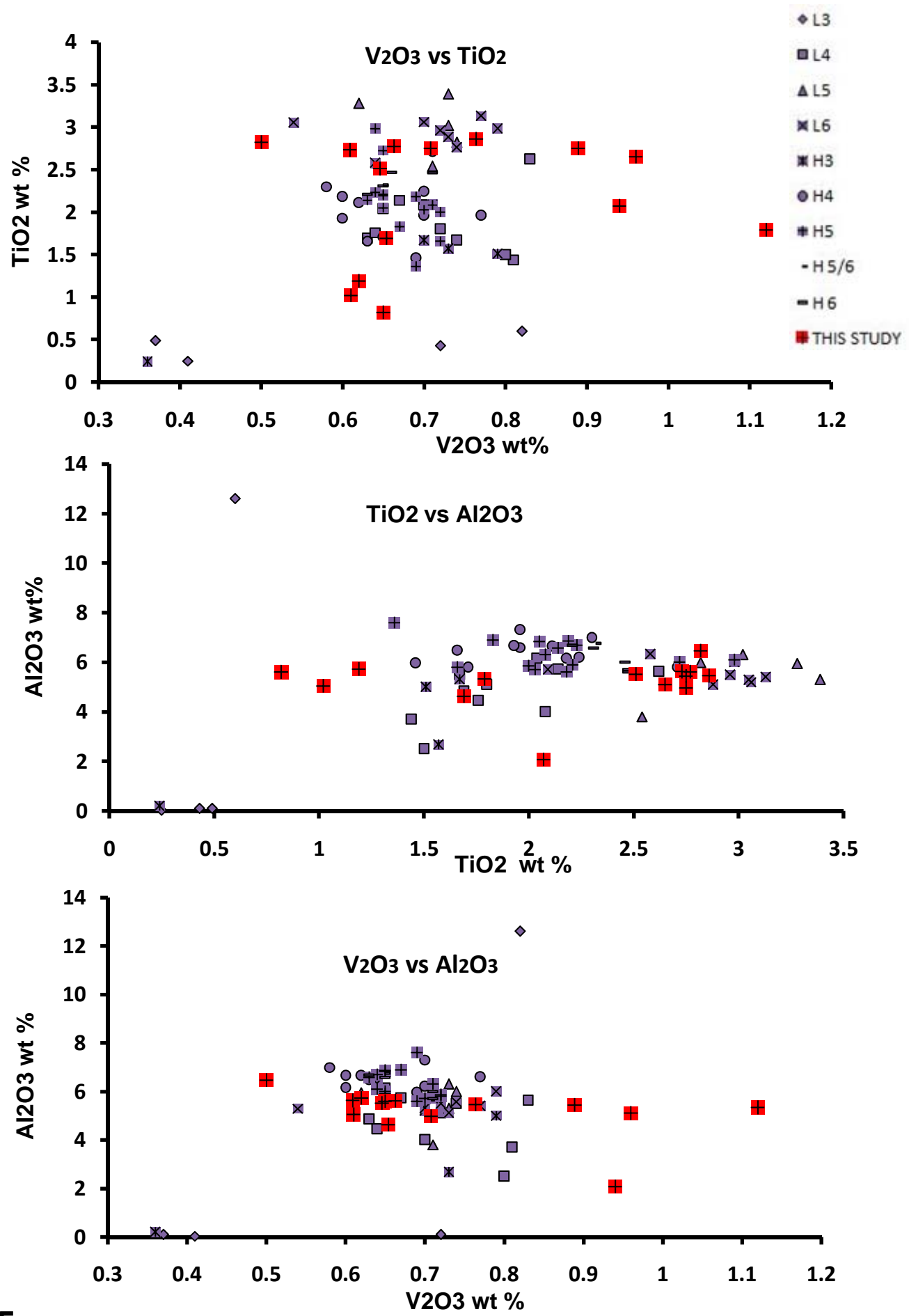

Fig. 5 



Fig. 5 

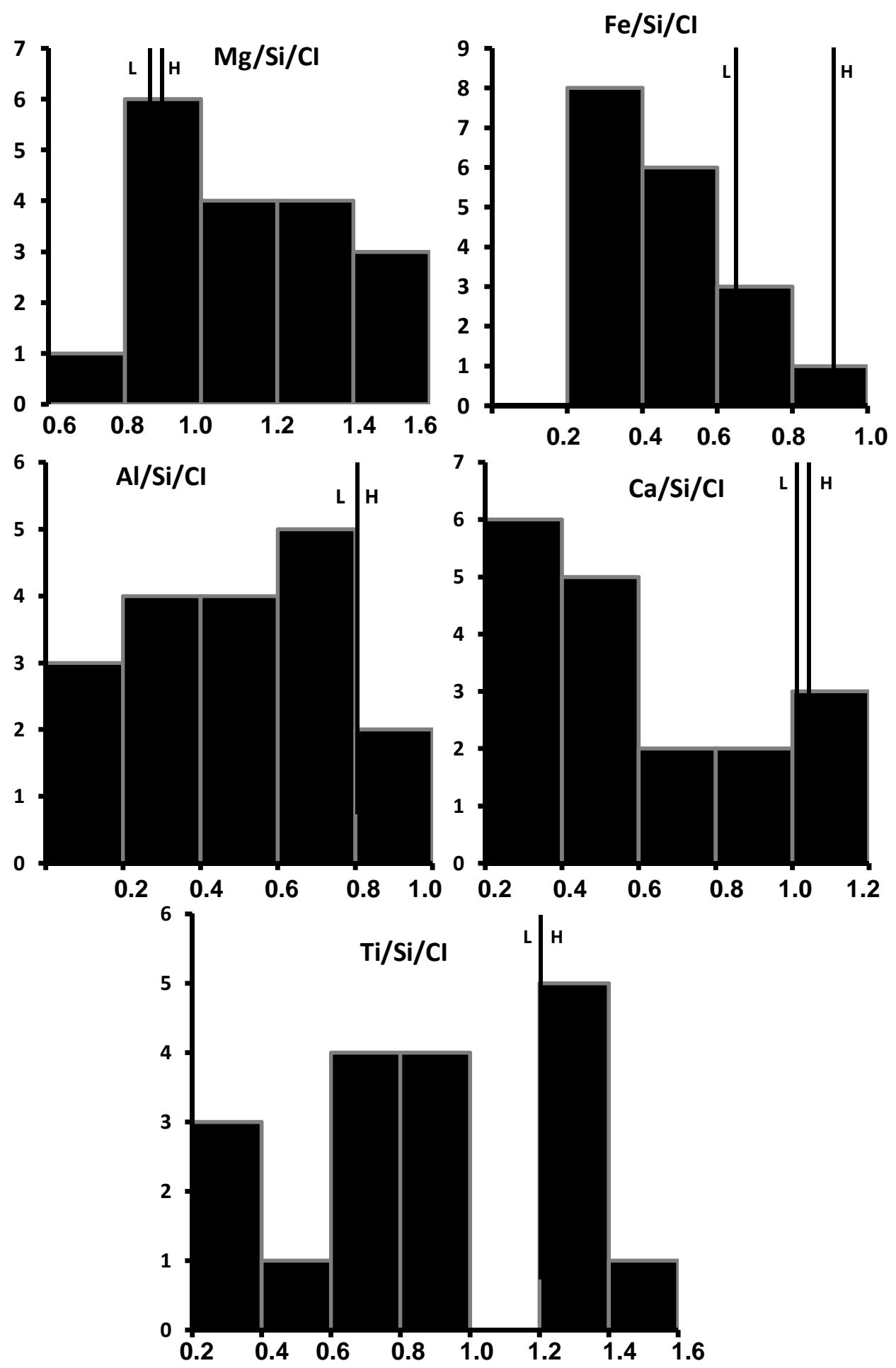

Fig. 6 


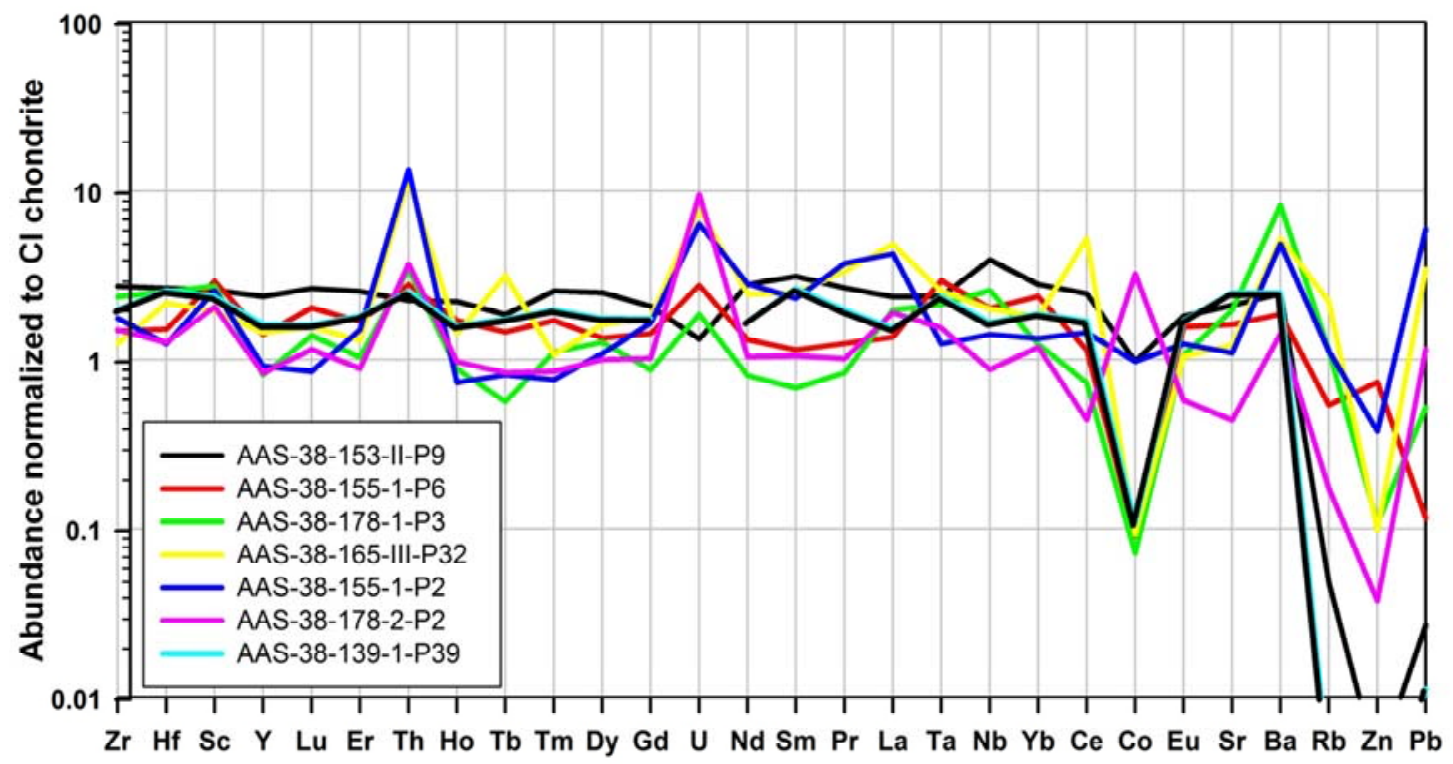

Fig. 7 
Table 1. Major oxide compositions (bulk) of relic grain bearing spherules (wt \%)

\begin{tabular}{|c|c|c|c|c|c|c|c|c|c|c|c|c|c|}
\hline & $\begin{array}{l}\text { Sample no and } \\
\text { size }\end{array}$ & $\mathrm{Na}_{2} \mathrm{O}$ & MgO & $\mathrm{Al}_{2} \mathrm{O}$ & $\mathrm{SiO}_{2}$ & $\begin{array}{l}\mathrm{Ca} \\
\mathrm{O}\end{array}$ & $\begin{array}{l}\text { TiO } \\
2\end{array}$ & $\mathrm{Cr}_{2} \mathrm{O}_{3}$ & MnO & $\mathrm{FeO}$ & $\mathrm{NiO}$ & Total & Remarks \\
\hline 1 & $\begin{array}{l}\text { AAS38-155-P2 } \\
(206 \mu \mathrm{m})\end{array}$ & 0.28 & $\begin{array}{l}24.6 \\
8\end{array}$ & 1.87 & $\begin{array}{l}35.8 \\
5\end{array}$ & 1.55 & 0.09 & 0.37 & 0.43 & $\begin{array}{l}34.2 \\
4\end{array}$ & 0.07 & 99.43 & Full dusty olivines \\
\hline 2 & $\begin{array}{l}\text { AAS-38-178-\#2- } \\
\text { P2 }(212 \mu \mathrm{m})\end{array}$ & 0.01 & $\begin{array}{l}38.6 \\
1\end{array}$ & 0.14 & $\begin{array}{l}37.9 \\
9\end{array}$ & 0.17 & 0.01 & 0.32 & 0.43 & $\begin{array}{l}24.4 \\
1\end{array}$ & 0.18 & 102.27 & Full dusty olivines \\
\hline 3 & $\begin{array}{l}\text { AAS38-139-P39 } \\
(270 \mu \mathrm{m})\end{array}$ & 0.17 & $\begin{array}{l}36.4 \\
1\end{array}$ & 0.56 & $\begin{array}{l}47.6 \\
8\end{array}$ & 0.34 & 0.08 & 0.04 & 0.40 & $\begin{array}{l}13.3 \\
8\end{array}$ & 0.01 & 99.07 & Dusty olivine inclusions \\
\hline 4 & $\begin{array}{l}\text { AAS38-153-P10 } \\
(272 \mu \mathrm{m})\end{array}$ & 0.46 & $\begin{array}{l}30.9 \\
6\end{array}$ & 2.37 & $\begin{array}{l}48.0 \\
3\end{array}$ & 1.1 & 0.15 & 0.23 & 0.45 & $\begin{array}{l}14.2 \\
9\end{array}$ & 0.08 & 98.12 & Dusty olivine inclusions \\
\hline 5 & 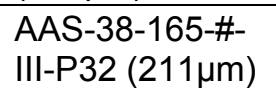 & 0.26 & $\begin{array}{l}35.6 \\
3\end{array}$ & 1.66 & $\begin{array}{l}43.4 \\
3\end{array}$ & 2.00 & 0.06 & 0.16 & 0.31 & $\begin{array}{l}17.6 \\
5\end{array}$ & 0.13 & 101.29 & $\begin{array}{l}\text { Dusty olivine and } \\
\text { chromite }\end{array}$ \\
\hline 6 & $\begin{array}{l}\text { AAS-62-54-P33 } \\
(279 \mu \mathrm{m})\end{array}$ & 0.31 & $\begin{array}{l}38.0 \\
6\end{array}$ & 2.02 & $\begin{array}{l}40.6 \\
3\end{array}$ & 0.58 & 0.12 & 0.48 & 0.34 & $\begin{array}{l}18.3 \\
9\end{array}$ & 0.08 & 101.01 & Dusty olivine inclusions \\
\hline 7 & $\begin{array}{l}\text { AAS38-165\#2- } \\
\text { P8 }(280 \mu \mathrm{m})\end{array}$ & 0.01 & $\begin{array}{l}44.7 \\
8\end{array}$ & 0.14 & $\begin{array}{l}40.1 \\
1\end{array}$ & 0.15 & 0.01 & 0.26 & 0.21 & $\begin{array}{l}17.1 \\
5\end{array}$ & 0.1 & 102.92 & $\begin{array}{l}\text { Porphyritic with dusty } \\
\text { olivine inclusions }\end{array}$ \\
\hline 8 & $\begin{array}{l}\text { AAS38-186-P14 } \\
(173 \mu \mathrm{m})\end{array}$ & \multicolumn{11}{|c|}{ Bulk composition not available, only dusty olivine analyzed } & $\begin{array}{l}\text { Porphyritic, has a large } \\
\text { Dusty Olivine inclusion }\end{array}$ \\
\hline 9 & $\begin{array}{l}\text { AAS63-54-P10 } \\
(308 \mu \mathrm{m})\end{array}$ & 0.31 & $\begin{array}{l}32.5 \\
2\end{array}$ & 2.31 & $\begin{array}{l}47.6 \\
5\end{array}$ & 0.63 & 0.09 & 0.09 & 0.38 & $\begin{array}{l}17.5 \\
5\end{array}$ & 0.04 & 101.57 & Chromite-bearing \\
\hline 10 & $\begin{array}{l}\text { AAS38-155-\#1- } \\
\text { P6 }(288 \mu \mathrm{m})\end{array}$ & 0.34 & $\begin{array}{l}29.7 \\
5\end{array}$ & 2.43 & 49.1 & 1.49 & 0.15 & 0.59 & 0.42 & $\begin{array}{l}17.7 \\
5\end{array}$ & 0.08 & 102.1 & Chromite-bearing \\
\hline 11 & $\begin{array}{l}\text { AAS38-178\#1- } \\
\text { P3 }(230 \mu \mathrm{m})\end{array}$ & 0.29 & $\begin{array}{l}42.1 \\
6\end{array}$ & 1.4 & $\begin{array}{l}43.6 \\
4\end{array}$ & 0.83 & 0.03 & 0.17 & 0.25 & $\begin{array}{l}11.8 \\
7\end{array}$ & 0.32 & 100.96 & Chromite-bearing \\
\hline 12 & $\begin{array}{l}\text { AAS38-153-ii\#1- } \\
\text { P9 }(443 \mu \mathrm{m})\end{array}$ & 0.07 & $\begin{array}{l}32.5 \\
4 \\
\end{array}$ & 1.07 & $\begin{array}{l}42.9 \\
7\end{array}$ & 0.22 & 0.07 & 0.29 & 0.31 & $\begin{array}{l}20.4 \\
7\end{array}$ & 0.63 & 98.64 & Chromite-bearing \\
\hline 13 & 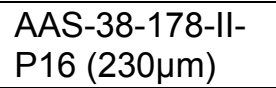 & 0.01 & 32.3 & 0.8 & 49.1 & 0.8 & 0.1 & 0.5 & 0.4 & 17 & 0.1 & 101.11 & Chromite-bearing \\
\hline 14 & $\begin{array}{l}\text { AAS38/147- } \\
\text { REMSPH-P11 } \\
(230 \mu \mathrm{m})\end{array}$ & 0.69 & $\begin{array}{l}27.7 \\
1\end{array}$ & 2.62 & $\begin{array}{l}43.8 \\
7\end{array}$ & 1.91 & 0.11 & 0.3 & 0.3 & 20 & 0.1 & 97.61 & Chromite-bearing \\
\hline
\end{tabular}


Table 2. Chemical compositions of chromites in micrometeorites (wt \%)

\begin{tabular}{|c|c|c|c|c|c|c|c|c|c|c|c|}
\hline & $\mathrm{SiO2}$ & MgO & $\mathrm{Al}_{2} \mathrm{O}$ & $\begin{array}{l}\text { TiO } \\
2\end{array}$ & $\mathrm{Cr}_{2} \mathrm{O}$ & $\begin{array}{l}\text { Mn } \\
0\end{array}$ & $\mathrm{FeO}$ & $\begin{array}{l}\mathrm{V}_{2} \mathrm{O} \\
5\end{array}$ & $\begin{array}{l}Z n \\
0\end{array}$ & Total & Possible parent meteorite \\
\hline AAS-38-153-II,\#1-P9 & 0.09 & $\begin{array}{l}12.8 \\
2\end{array}$ & 6.46 & 2.82 & 55.27 & 0.01 & $\begin{array}{l}20.1 \\
6\end{array}$ & 0.50 & $\begin{array}{l}0.2 \\
6\end{array}$ & 98.57 & L6 \\
\hline AAS-38-155-\#-P6 & 0.18 & 3.50 & 5.44 & 2.75 & 54.34 & 0.01 & $\begin{array}{l}30.4 \\
2\end{array}$ & 0.89 & $\begin{array}{l}0.4 \\
4\end{array}$ & 98.27 & L5, L6 \\
\hline AAS-38-155\#-P6 & 0.89 & 8.13 & 5.52 & 2.51 & 54.29 & 0.01 & $\begin{array}{l}24.7 \\
5\end{array}$ & 0.65 & $\begin{array}{l}0.2 \\
3\end{array}$ & 97.14 & L5, L6 \\
\hline AAS-38-155\#-P6 & 0.11 & 7.62 & 5.45 & 2.86 & 55.54 & 0.01 & $\begin{array}{l}23.7 \\
8\end{array}$ & 0.76 & $\begin{array}{l}0.0 \\
0\end{array}$ & 96.24 & L5, L6 \\
\hline AAS-38-155\#-P6 & 0.13 & 8.84 & 5.62 & 2.73 & 54.08 & 0.01 & $\begin{array}{l}21.9 \\
4\end{array}$ & 0.61 & $\begin{array}{l}0.2 \\
2\end{array}$ & 94.57 & L5,L6 \\
\hline AAS-38-155\#-P6 & 0.26 & 9.48 & 4.97 & 2.75 & 55.36 & 0.01 & $\begin{array}{l}21.5 \\
6\end{array}$ & 0.71 & $\begin{array}{l}0.2 \\
7\end{array}$ & 95.43 & L5,L6 \\
\hline AAS-38-155\#-P6 & 4.24 & $\begin{array}{l}10.1 \\
2\end{array}$ & 4.63 & 1.69 & 49.71 & 0.01 & $\begin{array}{l}23.2 \\
0\end{array}$ & 0.65 & $\begin{array}{l}0.2 \\
5\end{array}$ & 94.96 & L5,L6 \\
\hline AAS-38-155\#-P6 & 0.84 & $\begin{array}{l}12.4 \\
0\end{array}$ & 5.61 & 2.77 & 55.73 & 0.01 & $\begin{array}{l}18.2 \\
2\end{array}$ & 0.66 & $\begin{array}{l}0.1 \\
8\end{array}$ & 96.63 & L5,L6 \\
\hline AAS-38-178-\#1,-P3 & n.d. & $\begin{array}{l}10.9 \\
0\end{array}$ & 5.33 & 1.79 & 62.14 & 1.09 & $\begin{array}{l}17.6 \\
9\end{array}$ & 1.12 & n.a. & $\begin{array}{l}100.0 \\
6\end{array}$ & L3 \\
\hline AAS-38-178-\#1,-P3 & 3.82 & $\begin{array}{l}11.4 \\
3\end{array}$ & 5.04 & 1.02 & 49.40 & 0.01 & $\begin{array}{l}28.6 \\
7\end{array}$ & 0.61 & n.a. & $\begin{array}{l}100.0 \\
0\end{array}$ & L3(?) \\
\hline AAS-38-165-\#III-P32 & 0.58 & $\begin{array}{l}14.1 \\
6\end{array}$ & 5.10 & 2.65 & 60.96 & 0.01 & $\begin{array}{l}15.6 \\
9\end{array}$ & 0.96 & n.a. & $\begin{array}{l}100.1 \\
1\end{array}$ & $\begin{array}{l}\mathrm{L} 6 \text { or } \mathrm{H} 3(?) \text { Chromite in dusty } \\
\text { olivine bearing spherule }\end{array}$ \\
\hline AAS62-54-P10 & $\begin{array}{l}10.4 \\
5\end{array}$ & $\begin{array}{l}14.9 \\
0\end{array}$ & 5.60 & 0.82 & 50.86 & 0.43 & $\begin{array}{l}16.7 \\
1\end{array}$ & 0.65 & n.a. & $\begin{array}{l}100.6 \\
4\end{array}$ & L3 \\
\hline $\begin{array}{l}\text { AAS38/147- } \\
\text { REMSPH/P11 }\end{array}$ & 1.49 & 12.3 & 5.73 & 1.19 & 59.44 & 0.27 & $\begin{array}{l}18.6 \\
9\end{array}$ & 0.62 & n.a. & 99.78 & $\mathrm{~L} 3 / \mathrm{H} 4$ \\
\hline AAS-38-178-II-P16 & 0.01 & 3.68 & 2.07 & 2.07 & 59.72 & 0.94 & $\begin{array}{l}27.0 \\
8\end{array}$ & 0.94 & $\begin{array}{l}0.3 \\
4\end{array}$ & $\begin{array}{l}100.0 \\
1\end{array}$ & H3/L4 \\
\hline
\end{tabular}

n.a.= not analyzed 
Table 3 : Chemical compositions of Rims and Cores of dusty olivine grains in spherules (wt \%)

\begin{tabular}{|c|c|c|c|c|c|c|c|c|c|c|c|c|c|}
\hline SAMPLE NO & $\mathrm{MgO}$ & $\mathrm{Al} 2 \mathrm{O} 3$ & $\mathrm{SiO} 2$ & $\mathrm{CaO}$ & $\mathrm{TiO} 2$ & $\mathrm{Cr} 2 \mathrm{O} 3$ & $\mathrm{MnO}$ & $\mathrm{FeO}$ & $\mathrm{NiO}$ & Total & Fo (mole\%) & $\begin{array}{l}\text { Fa } \\
\text { (mole\%) }\end{array}$ & Portion of grain analyzed \\
\hline \multirow{12}{*}{ AAS38-155-remsph-p2 } & 36.35 & 0.2 & 37.9 & 0.2 & 0.02 & 0.26 & 0.36 & 22.43 & 0.15 & 98.02 & 74.28 & 25.72 & Grain 1 RIM \\
\hline & 29.95 & 0.08 & 36.96 & 0.24 & 0.01 & 0.45 & 0.37 & 31.08 & 0.07 & 99.34 & 63.2 & 36.80 & Grain 1 CORE \\
\hline & 39.34 & 0.12 & 37.9 & 0.18 & 0.01 & 0.3 & 0.32 & 21.51 & 0.11 & 99.9 & 76.52 & 23.48 & Grain 2 RIM \\
\hline & 25.2 & 0.45 & 34.24 & 0.24 & 0.02 & 0.82 & 0.43 & 38.18 & 0.29 & 100.03 & 54.06 & 45.94 & Grain 2 CORE \\
\hline & 36.89 & 0.13 & 37.99 & 0.24 & 0.01 & 0.53 & 0.35 & 21.42 & 0.15 & 97.97 & 75.42 & 24.58 & Grain 4 RIM \\
\hline & 29.71 & 0.04 & 36.36 & 0.17 & 0.01 & 0.24 & 0.39 & 31.4 & 0.01 & 98.39 & 62.79 & 37.21 & Grain 4 CORE \\
\hline & 35.18 & 1.03 & 38.07 & 1.0 & 0.07 & 0.33 & 0.26 & 21.71 & 0.03 & 98.1 & 74.28 & 25.72 & Grain 5 RIM \\
\hline & 29.63 & 0.05 & 35.31 & 0.28 & 0.01 & 0.22 & 0.55 & 31.86 & 0.01 & 97.99 & 62.38 & 37.62 & Grain 5 CORE \\
\hline & 32.38 & 0.21 & 35.84 & 0.24 & 0.01 & 0.37 & 0.35 & 26.99 & 0.14 & 96.71 & 68.13 & 31.87 & Grain 6 RIM \\
\hline & 28.7 & 0.15 & 35.54 & 0.36 & 0.04 & 0.23 & 0.47 & 31.39 & 0.06 & 97.08 & 61.98 & 38.02 & Grain 6 CORE \\
\hline & 11.69 & 0.32 & 32.31 & 0.4 & 0.04 & 0.18 & 0.61 & 52.01 & 0.1 & 97.9 & 30.09 & 69.91 & FAYALITE Inclusion \\
\hline & 8.56 & 3.59 & 49.78 & 3.84 & 0.19 & 0.36 & 0.57 & 32.09 & 0.04 & 99.26 & 32.22 & 67.78 & Pyroxene in Dusty Olivine \\
\hline \multirow{2}{*}{ AAS38-139-P39 } & 44.28 & 0.19 & 45.10 & 0.10 & 0.04 & 0.05 & 0.38 & 9.29 & 0.03 & 99.62 & 89.47 & 10.53 & Rim \\
\hline & 41.57 & 0.05 & 39.55 & 0.02 & 0.04 & 0.00 & 0.35 & 17.23 & 0.06 & 98.89 & 81.14 & 18.86 & CORE \\
\hline \multirow{4}{*}{ AAS38-153-P10 } & 50.8 & 0.14 & 41.19 & 0.07 & 0.03 & 0.2 & 0.16 & 6.78 & 0.08 & 99.51 & 93.03 & 6.97 & $\operatorname{Rim}$ \\
\hline & 41.22 & 0.02 & 38.88 & 0.01 & 0.01 & 0.04 & 0.38 & 18.43 & 0.03 & 99.07 & 79.94 & 20.06 & Grain 1 CORE \\
\hline & 46.4 & 0.7 & 45.98 & 0.15 & 0.01 & 0.15 & 0.23 & 7.76 & 0.04 & 101.52 & 91.43 & 8.58 & Grain 2 RIM \\
\hline & 43.09 & 0.02 & 39.81 & 0.01 & 0.06 & 0.03 & 0.37 & 17.09 & 0.01 & 100.54 & 81.79 & 18.21 & Grain 2 CORE \\
\hline \multirow{2}{*}{ AAS-38-165-\#-III-P32 } & 49.81 & 0.07 & 41.05 & 0.13 & 0.01 & 0.12 & 0.22 & 9.57 & 0.28 & 101.34 & 90.27 & 9.73 & $\operatorname{Rim}$ \\
\hline & 38.55 & 0.01 & 38.64 & 0.02 & 0.02 & 0.03 & 0.45 & 23.77 & 0.07 & 101.70 & 74.29 & 25.71 & CORE \\
\hline \multirow{6}{*}{ AAS-38-178-\#2-P2 } & 43.42 & 0.16 & 39.06 & 0.05 & 0.01 & 0.44 & 0.26 & 18.97 & 0.16 & 102.66 & 80.31 & 19.69 & Grain I Rim \\
\hline & 36.19 & 0.47 & 38.02 & 0.29 & 0.01 & 0.56 & 0.57 & 25.45 & 0.01 & 101.74 & 71.71 & 28.29 & Grain 1 CORE \\
\hline & 42.02 & 0.11 & 38.62 & 0.02 & 0.01 & 0.27 & 0.30 & 21.22 & 0.11 & 102.84 & 77.92 & 22.08 & Grain 2 RIM \\
\hline & 35.62 & 0.05 & 37.61 & 0.39 & 0.01 & 0.56 & 0.58 & 27.67 & 0.14 & 102.76 & 69.65 & 30.35 & Grain 2 CORE \\
\hline & 43.94 & 0.09 & 39.21 & 0.07 & 0.01 & 0.48 & 0.41 & 18.84 & 0.16 & 103.43 & 80.61 & 19.39 & Grain 3 RIM \\
\hline & 39 & 0.05 & 38.46 & 0.15 & 0.01 & 0.20 & 0.55 & 23.55 & 0.16 & 102.22 & 74.70 & 25.30 & Grain 3 CORE \\
\hline
\end{tabular}


Table 4. Porphyritic Olivine Pyroxene spherule AAS38-186-P8 : Olivine and Pyroxene compositions (18 grains and matrix)

\begin{tabular}{|c|c|c|c|c|c|c|c|c|c|c|}
\hline $\mathrm{MgO}$ & $\mathrm{Al} 2 \mathrm{O} 3$ & SiO2 & $\mathrm{CaO}$ & TiO2 & Cr2O3 & MnO & $\mathrm{FeO}$ & $\mathrm{NiO}$ & Total & Remarks \\
\hline 44.76 & 0.14 & 39.83 & 0.24 & 0.02 & 0.57 & 0.33 & 12.47 & 0.26 & 98.71 & Olivine \\
\hline 34.35 & 1.10 & 56.36 & 0.86 & 0.11 & 0.66 & 0.17 & 5.97 & 0.04 & 99.69 & Pyroxene \\
\hline 34.29 & 0.86 & 56.93 & 0.89 & 0.09 & 0.73 & 0.21 & 5.57 & 0.02 & 99.60 & Pyroxene \\
\hline 44.01 & 0.58 & 43.12 & 0.44 & 0.04 & 0.34 & 0.29 & 10.94 & 0.02 & 99.84 & Olivine \\
\hline 42.95 & 0.28 & 47.24 & 0.26 & 0.02 & 0.48 & 0.19 & 8.54 & 0.07 & 99.98 & Olivine \\
\hline 39.21 & 1.7 & 43.26 & 1.24 & 0.08 & 0.42 & 0.28 & 14.42 & 0.01 & 100.62 & Olivine \\
\hline 48.72 & 0.08 & 40.77 & 0.19 & 0.02 & 0.36 & 0.3 & 10.53 & 0.01 & 100.98 & Olivine \\
\hline 36.45 & 0.01 & 51.06 & 1.01 & 0.15 & 0.7 & 0.31 & 9.93 & 0.01 & 99.63 & Pyroxene \\
\hline 34.85 & 0.79 & 57.29 & 0.93 & 0.09 & 0.79 & 0.15 & 5.81 & 0.04 & 100.75 & Pyroxene \\
\hline 33.18 & 1.39 & 57.7 & 0.98 & 0.14 & 0.75 & 0.12 & 5.77 & 0.01 & 100.04 & Pyroxene \\
\hline 34.77 & 0.81 & 58.35 & 0.66 & 0.07 & 0.71 & 0.1 & 3.95 & 0.05 & 99.6 & Pyroxene \\
\hline 37.15 & 0.97 & 53.38 & 0.75 & 0.06 & 0.68 & 0.2 & 5.79 & 0.03 & 99.08 & Pyroxene \\
\hline 30.3 & 1.36 & 56.14 & 1.15 & 0.12 & 0.8 & 0.26 & 10.15 & 0.06 & 100.39 & Pyroxene \\
\hline 34.2 & 1.37 & 56.85 & 1.33 & 0.12 & 0.89 & 0.1 & 5.24 & 0.12 & 100.3 & Pyroxene \\
\hline 50.96 & 0.03 & 41.74 & 0.09 & 0.01 & 0.39 & 0.17 & 6.09 & 0.02 & 99.48 & Olivine \\
\hline 47.57 & 0.03 & 41.96 & 0.14 & 0.02 & 0.41 & 0.26 & 9.65 & 0.05 & 99.97 & Olivine \\
\hline 46.02 & 0.49 & 43.88 & 0.25 & 0.04 & 0.45 & 0.18 & 8.96 & 0.03 & 100.39 & Olivine \\
\hline 34.59 & 0.70 & 57.40 & 0.95 & 0.07 & 0.77 & 0.10 & 5.03 & 0.01 & 99.62 & Pyroxene \\
\hline 24.90 & 2.86 & 43.32 & 2.30 & 0.13 & 0.49 & 0.28 & 24.55 & 0.06 & 99.40 & $\begin{array}{l}\text { MATRIX } \\
\text { AVERAGE }\end{array}$ \\
\hline
\end{tabular}


Table 5 : Trace Element Compositions of micrometeorites (ppm)

\begin{tabular}{|c|c|c|c|c|c|c|c|}
\hline Element & $\frac{\text { AAS-38- }}{153-11-P 9}$ & $\frac{\text { AAS-38- }}{155-1-P 6}$ & $\frac{\text { AAS-38- }}{178-1-P 3}$ & $\begin{array}{l}\text { AAS-38- } \\
165-111-P 32\end{array}$ & $\frac{\text { AAS-38- }}{155-1-P 2}$ & $\frac{\text { AAS-38- }}{178-2-P 2}$ & $\frac{\text { AAS-38- }}{139-1-P 39}$ \\
\hline $\mathrm{Zr}$ & 10.40 & 5.69 & 9.01 & 4.78 & 6.73 & 5.76 & 7.58 \\
\hline $\mathrm{Hf}$ & 0.27 & 0.16 & 0.26 & 0.22 & 0.13 & 0.13 & 0.27 \\
\hline Sc & 15.28 & 17.30 & 16.22 & 11.47 & 15.19 & 12.20 & 14.06 \\
\hline $\mathbf{Y}$ & 3.73 & 2.22 & 1.28 & 2.27 & 1.44 & 1.31 & 2.54 \\
\hline Lu & 0.07 & 0.05 & 0.03 & 0.04 & 0.02 & 0.03 & 0.04 \\
\hline $\mathrm{Er}$ & 0.41 & 0.27 & 0.17 & 0.21 & 0.24 & 0.14 & 0.29 \\
\hline Th & 0.07 & 0.08 & 0.10 & 0.34 & 0.39 & 0.11 & 0.07 \\
\hline Ho & 0.12 & 0.09 & 0.05 & 0.08 & 0.04 & 0.05 & 0.09 \\
\hline Tb & 0.07 & 0.05 & 0.02 & 0.11 & 0.03 & 0.03 & 0.06 \\
\hline $\mathrm{Tm}$ & 0.06 & 0.04 & 0.03 & 0.03 & 0.02 & 0.02 & 0.05 \\
\hline Dy & 0.62 & 0.33 & 0.31 & 0.40 & 0.27 & 0.25 & 0.44 \\
\hline Gd & 0.41 & 0.29 & 0.17 & 0.35 & 0.33 & 0.20 & 0.35 \\
\hline U & 0.01 & 0.02 & 0.01 & 0.06 & 0.05 & 0.08 & 0.01 \\
\hline Nd & 1.28 & 0.60 & 0.37 & 1.12 & 1.29 & 0.48 & 0.77 \\
\hline Sm & 0.46 & 0.17 & 0.10 & 0.37 & 0.34 & 0.16 & 0.39 \\
\hline $\operatorname{Pr}$ & 0.25 & 0.12 & 0.08 & 0.31 & 0.35 & 0.09 & 0.18 \\
\hline La & 0.56 & 0.32 & 0.47 & 1.14 & 1.00 & 0.45 & 0.37 \\
\hline $\mathrm{Ta}$ & 0.03 & 0.04 & 0.03 & 0.03 & 0.02 & 0.02 & 0.03 \\
\hline $\mathrm{Nb}$ & 0.94 & 0.49 & 0.62 & 0.48 & 0.34 & 0.21 & 0.40 \\
\hline Yb & 0.45 & 0.38 & 0.20 & 0.29 & 0.22 & 0.19 & 0.30 \\
\hline $\mathrm{Ce}$ & 1.51 & 0.70 & 0.45 & 3.22 & 0.89 & 0.27 & 1.04 \\
\hline Co & 489.43 & 45.11 & 35.74 & 46.26 & 487.39 & 1612.95 & 54.03 \\
\hline Eu & 0.10 & 0.09 & 0.06 & 0.06 & 0.07 & 0.03 & 0.10 \\
\hline $\mathrm{Sr}$ & 15.21 & 11.73 & 14.24 & 8.85 & 7.96 & 3.18 & 18.16 \\
\hline $\mathrm{Ba}$ & 5.95 & 4.49 & 19.84 & 12.63 & 11.70 & 3.42 & 6.03 \\
\hline $\mathbf{R b}$ & 0.11 & 1.24 & 2.62 & 5.09 & 2.59 & 0.40 & 0.01 \\
\hline $\mathrm{Zn}$ & 1.22 & 227.95 & 33.34 & 30.33 & 117.36 & 11.58 & 0.28 \\
\hline $\mathrm{Pb}$ & 0.07 & 0.28 & 1.29 & 8.51 & 14.69 & 2.85 & 0.03 \\
\hline
\end{tabular}

